M. Thomas, Münster (federführend)

M. Baumann, Dresden

M. Deppermann, Berlin

L. Freitag, Hermer

U. Gatzemeier, Großhansdorf

R. Huber, München

B. Passlick, München-Gauting

M. Serke, Berlin

D. Ukena, Homburg

\section{Empfehlungen zur Therapie des Bronchialkarzinoms}

Gemeinsame Empfehlung

der Deutschen Gesellschaft für Pneumologie (DGP), der Deutschen Gesellschaft für Radioonkologie (DEGRO),

der Deutschen Gesellschaft für Thoraxchirurgie (DGT)

und der Arbeitsgemeinschaft Internistische Onkologie

in der Deutschen Krebsgesellschaft (AIO)

Recommendations on the Therapy of Bronchial Carcinoma

\section{Zusammenfassung}

Zur Festlegung der Therapiestrategie wird beim kleinzelligen wie nicht-kleinzelligen Bronchialkarzinom die Stadieneinteilung nach dem internationalen Staging-System empfohlen. Beim kleinzelligen Bronchialkarzinom sollte möglichst immer mit einer Polychemotherapie (4-6 Zyklen) behandelt und bei fehlendem Ansprechen umgehend auf eine nicht kreuzresistente Alternativkombination gewechselt werden. Im Stadium I- III umfasst das therapeutische Vorgehen darüber hinaus Maßnahmen zur lokalen Tumorkontrolle. Neben der Möglichkeit der Operation in den Stadien I- IIIA ist dies in der Regel die thorakale Radiotherapie. Im Falle der alleinigen Radiotherapie, sollte diese möglichst frühzeitig simultan zur Chemotherapie erfolgen. Nach Erreichen einer Vollremission wird eine adjuvante Ganzschädelbestrahlung empfohlen. Im Stadium I- IIIA des nicht-kleinzelligen Bronchialkarzinoms ist die komplette Resektion des Primärtumors und umfassende mediastinale Lymphadenektomie grundlegend für eine kurative Therapieoption. Der Stellenwert einer zusätzlichen systemischen Therapie wird derzeit in randomisierten Studien überprüft. Im Stadium III sind die Therapiekonzepte derzeit im Fluss und daher eine Behandlung im Rahmen von randomisierten Studien sinnvoll. Außerhalb von Studien wird für inoperable Patienten eine Sequenz aus einer Platin-haltigen Polychemotherapie und nachfolgenden Radiotherapie empfohlen. Bei inoperablen Patienten, die keine Kandidaten für eine Chemoradiotherapie sind, wird eine alleinige, kurativ intendierte Radiotherapie empfohlen. Für Patienten mit Fernmetastasen - und hinreichendem Allgemeinzustand sowie fehlender eine solche Behandlung ausschließenden Komorbidität - werden zunächst zwei Zyklen einer Platin-haltigen Polychemotherapie und symptomenorientiert ggf. zusätzliche strahlentherapeutische oder chiurgische Maßnahmen empfohlen. Im Falle eines Ansprechens
(Symptomenreduktion; Tumorverkleinerung über $50 \%$ ) sollte die Chemotherapie auf vier bis sechs Behandlungszyklen ausgedehnt werden. Nach abgeschlossener kurativer Behandlung wird in den ersten beiden Jahren zu 3-monatigen und dann für weitere drei Jahre zu 6-monatigen Nachsorgeintervallen geraten.

\section{Einleitung}

Für die Prognose sowie die therapeutische Strategie ist die Differenzierung zwischen kleinzelligen (SCLC) Bronchialkarzinomen (Häufigkeit 20\%) und nicht-kleinzelligen (NSCLC) Bronchialkarzinomen (Häufigkeit $80 \%$ ) wesentlich. Zudem sind neben der Histologie und der anatomischen Tumorausdehnung eine prätherapeutische Gewichtsabnahme sowie der Leistungsindex des Patienten für die Prognose wie auch die individuelle therapeutische Entscheidung bedeutsam. Das therapeutische Vorgehen erfolgt stadienadaptiert. Sowohl für kleinzellige wie auch nichtkleinzellige Bronchialkarzinome wird die Stadieneinteilung nach dem Internationalen Staging-System (ISS) empfohlen (vgl. Tab. 1 und 2) [1,2]. 
Tab. 1 TNM-Deskriptoren

\begin{tabular}{|c|c|}
\hline \multicolumn{2}{|c|}{ T-Status } \\
\hline$T X$ & $\begin{array}{l}\text { Zytologischer Malignomnachweis in Sputum oder bronchialer } \\
\text { Spülflüssigkeit (Bronchialsekret; bronchoalveoläre Lavage) ohne } \\
\text { Tumornachweis in der Bronchoskopie oder Schnittbilddiagnostik. }\end{array}$ \\
\hline TO & Kein Primärtumornachweis. \\
\hline Tis & Carcinoma in situ. \\
\hline$T 1$ & $\begin{array}{l}\text { Tumor } \leq 3 \mathrm{~cm} \text {, umgeben von Lunge oder viszeraler Pleura. } \\
\text { Bronchoskopisch kein Hinweis für eine Infiltration proximal eines } \\
\text { Lappenbronchus. }\end{array}$ \\
\hline$T 2$ & $\begin{array}{l}\text { Tumor mit a) einer Größe }>3 \mathrm{~cm} \text {; b) Befall des Hauptbronchus, je- } \\
\text { doch } \geq 2 \mathrm{~cm} \text { distal der Hauptkarina; c) Infiltration der viszeralen } \\
\text { Pleura; d) assoziierter Atelektase, aber nicht der ganzen Lunge. }\end{array}$ \\
\hline T3 & $\begin{array}{l}\text { Tumor a) jeder Größe mit direkter Infiltration von Brustwand, } \\
\text { Zwerchfell, parietalem Perikard oder mediastinaler Pleura; } \\
\text { b) Hauptbronchusbefall }<2 \mathrm{~cm} \text { distal der Hauptkarina, jedoch nicht } \\
\text { der Hauptkarina selbst; c) mit Atelektase der ganzen Lunge. }\end{array}$ \\
\hline$T 4$ & $\begin{array}{l}\text { Tumor jeder Größe mit Infiltration von Mediastinum, Herz, großen } \\
\text { Gefäßen, Trachea, Ösophagus, Wirbelkörper, Hauptkarina oder Tu- } \\
\text { mor mit malignem Pleuraerguss oder Tumor mit Satellitenherden } \\
\text { im ipsilateralen tumortragenden Lungenlappen. }\end{array}$ \\
\hline \multicolumn{2}{|c|}{ N-Status } \\
\hline$N X$ & Regionale Lymphknoten nicht hinreichend untersucht. \\
\hline NO & Kein Nachweis regionärer Lymphknotenmetastasen. \\
\hline N 1 & Ipsilateral peribronchial/hilär Lymphknotenmetastasen. \\
\hline$N 2$ & $\begin{array}{l}\text { Ipsilateral mediastinal und/oder subkarinal Lymphknoten- } \\
\text { metastasen. }\end{array}$ \\
\hline N3 & $\begin{array}{l}\text { Kontralateral mediastinal/hilär Lymphknotenmetastasen und/oder } \\
\text { in ipsi-/kontralateralen Skalenus- oder supraklavikularen Lymph- } \\
\text { knoten. }\end{array}$ \\
\hline \multicolumn{2}{|c|}{ M-Status } \\
\hline$M X$ & $\begin{array}{l}\text { Untersuchungen zum Ausschluss von Fernmetastasen nicht } \\
\text { hinreichend durchgeführt. }\end{array}$ \\
\hline MO & Keine Fernmetastasen. \\
\hline$M 1$ & Fernmetastasen. \\
\hline
\end{tabular}

Stadienabhängige Therapie

des kleinzelligen Bronchialkarzinoms

\section{Stadium I- III}

Das therapeutische Vorgehen umfasst (vgl. Tab. 3)

- die Durchführung einer zytostatischen Polychemotherapie über 4-6 Zyklen.

- die Durchführung einer lokoregionären Radiotherapie unter Einschluss von Primärtumor und mediastinalem sowie ggf. supraclavikulärem Lymphabflussgebiet. In der Regel erfolgt diese bisher nach Abschluss der Chemotherapie. In Metaanalysen randomisierter Studien ist für dieses sequenzielle Vorgehen im Vergleich zur alleinigen Chemotherapie eine Steigerung der 2- bzw. 3-Jahres-Überlebensrate von $5 \%$ belegt [3,4]. Drei von fünf randomisierten Studien [5-10] lassen für den frühzeitigen Einsatz einer Radiotherapie simultan zur Chemotherapie eine weitere Verbesserung der 3-Jahres-Überlebensrate von $8-10 \%$ im Vergleich zu dem sequenziellen Vorgehen erkennen $(29,7 \%$ vs. $21,5 \% ; 48 \%$ vs. $39 \%$; $30,9 \%$ vs. 20,7\%) [5-7]. Daher kann die frühzeitige Radiotherapie simultan zur Chemotherapie empfohlen werden. Darüber hinaus scheint, zumindest nach den Daten einer randomisierten Studie, durch eine akzelerierte Hyperfraktionierung der Radiotherapie, mit Beginn simultan zum 1.Zyklus der Chemotherapie, eine weitere Verbesserung der Langzeitüberlebensrate möglich (5-Jahres-Überlebensrate $26 \%$ vs. 16\%) [11] .

- nach Erreichen einer Vollremission die Durchführung einer adjuvanten Ganzschädelbestrahlung. Diese führt gemäß einer Metaanalyse randomisierter Studien nach 3 Jahren zu einer signifikanten Senkung der kumulativen Inzidenz von Hirnmetastasen (58,6\% vs. 33,3\%), sowie einem signifikanten Überlebensvorteil (3-Jahres-Überlebensrate $20,7 \%$ vs. $15,3 \%$ ) [12].

- die anatomische Resektion mit nachfolgender Chemotherapie, wenn sich bei der operativen Abklärung eines Rundherdes unklarer Ätiologie im Schnellschnitt Anteile eines kleinzelligen Karzinomes zeigen. Bei einem Rundherd mit vergrößerten mediastinalen Lymphknoten wird die diagnostische Mediastinoskopie durchgeführt.

Tab. 2 5-Jahres-Überlebensraten von Patienten mit nicht-kleinzelligem Bronchialkarzinom gemäß Zuordnung zum Internationalen Staging-System (ISS) nach TNM-Deskriptoren (nach [1])

\begin{tabular}{|c|c|c|c|c|c|c|}
\hline \multirow{2}{*}{\multicolumn{2}{|c|}{ ISS-Stadium }} & \multirow{2}{*}{\multicolumn{3}{|c|}{$T N M$}} & \multirow{2}{*}{\multicolumn{2}{|c|}{ 5-Jahres-Überlebensrate }} \\
\hline & & & & & & \\
\hline \multirow[t]{2}{*}{ Stadium } & $I A$ & $\mathrm{~T} 1$ & NO & M0 & $61 \%$ & $67 \%$ \\
\hline & IB & $\mathrm{T} 2$ & NO & M0 & $38 \%$ & $57 \%$ \\
\hline \multirow[t]{3}{*}{ Stadium } & $\| A$ & $\mathrm{~T} 1$ & N1 & M0 & $34 \%$ & $55 \%$ \\
\hline & $\| B$ & $\mathrm{~T} 2$ & N1 & M0 & $24 \%$ & $39 \%$ \\
\hline & & $\mathrm{T} 3$ & NO & M0 & $22 \%$ & $38 \%$ \\
\hline \multirow[t]{2}{*}{ Stadium } & IIIA & $\mathrm{T} 3$ & N1 & M0 & $9 \%$ & $25 \%$ \\
\hline & & $\mathrm{T} 1-3$ & N2 & M0 & $13 \%$ & $23 \%$ \\
\hline \multirow[t]{2}{*}{ Stadium } & IIIB & $\mathrm{T} 4$ & N0 -2 & M0 & $7 \%$ & - \\
\hline & & $\mathrm{T} 1-4$ & N3 & M0 & $3 \%$ & - \\
\hline Stadium & IV & $\mathrm{T} 1-4$ & No-3 & M1 & $1 \%$ & - \\
\hline
\end{tabular}

* Überlebensraten nach operativer Behandlung mit chirurgischer Verifikation des Stadiums und histomorphologischer Bestätigung
Im Falle einer chirurgischen Resektion zur lokoregionären Tumorkontrolle werden im Stadium I bzw. II gemäß ISS in Sammelstatistiken 5-Jahres-Überlebensraten von 50 bzw. 35\% angegeben [13 - 15]. Ein operatives Vorgehen in diesen Stadien - jedoch in Verbindung mit einer neoadjuvanten oder adjuvanten Chemotherapie und ggf. Radiotherapie - kann daher empfohlen werden [16].

Bei intendierter Operation sollte prätherapeutisch eine eindeutige Festlegung des Stadiums unter Einschluss von Mediastinoskopie und Knochenmarkbiopsie (neben Schädel-, Thorax-, Abdomen-CT und Skelettszintigramm) erfolgen. Zur Festlegung des Biopsieortes der Knochenmarkbiopsie kann die Knochenmarkszintigraphie hilfreich sein. Der Stellenwert der mediastinalen Nachbestrahlung nach chirurgischer Resektion im Stadium I/II ist derzeit offen. Die Ergebnisse der postoperativen Radiotherapie beim NSCLC können aufgrund der unterschiedlichen Tumorbiologie nicht direkt auf das SCLC übertragen werden. Bis zum Vorliegen valider Daten wird außerhalb von Studien die postoperative Strahlentherapie ab einer N2-Situation oder im Falle einer inkompletten Tumorresektion empfohlen. 
Tab. 3 Kleinzelliges Bronchialkarzinom: Therapie gemäß Stadium

\begin{tabular}{|c|c|c|c|}
\hline Stadium & $\begin{array}{l}\text { derzeit überwiegend } \\
\text { praktizierte Therapie }\end{array}$ & Empfehlung & Möglichkeiten zur prognoserelevanten Verbesserung der Therapie \\
\hline 1 & $\begin{array}{l}\mathrm{OP} \rightarrow \mathrm{CT} \rightarrow \mathrm{PCl} \text { bzw. } \\
\mathrm{CT} \rightarrow \mathrm{TRT}+\mathrm{PCl} \text { (falls CR) }\end{array}$ & $\begin{array}{l}\mathrm{OP} \rightarrow \mathrm{CT} \rightarrow \mathrm{PCl} \text { bzw. } \\
\mathrm{CT} / \mathrm{TRT}+\mathrm{PCl} \text { (falls CR) } \\
\text { Behandlung in Studien* }\end{array}$ & Therapieoptimierung in multimodalen Konzepten \\
\hline II & $\begin{array}{l}\mathrm{OP} \rightarrow \mathrm{CT} \rightarrow \mathrm{TRT} \rightarrow \mathrm{PCl} \text { bzw. } \\
\mathrm{CT} \rightarrow \mathrm{TRT}+\mathrm{PCl}(\text { falls } \mathrm{CR} \text { ) }\end{array}$ & $\begin{array}{l}\mathrm{OP} \rightarrow \mathrm{CT} \rightarrow \mathrm{TRT} \rightarrow \mathrm{PCl} \text { bzw. } \\
\mathrm{CT} / \mathrm{TRT}+\mathrm{PCl} \text { (falls CR) } \\
\text { Behandlung in Studien* }\end{array}$ & $\begin{array}{l}\text { Verbesserung der lokalen Kontrolle durch: } \\
\text { a) Überprüfung des Stellenwertes der Resektion im Stadium I- IIIA } \\
\text { b) Überprüfung von Bestrahlungskonzepten } \\
\text { (Fraktionierung, Zielvolumen, Gesamtdosis) im Stadium I- IIIB }\end{array}$ \\
\hline IIIA & $\mathrm{CT} \rightarrow \mathrm{TRT}+\mathrm{PCl}$ (falls CR) & $\begin{array}{l}\mathrm{CT} / \mathrm{TRT}+\mathrm{PCl} \text { (falls CR) } \\
\text { Behandlung in Studien* }\end{array}$ & $\begin{array}{l}\text { Verbesserung der systemischen Kontrolle durch: } \\
\text { a) Überprüfung des Stellenwertes der Hochdosischemotherapie } \\
\text { im Stadium I- IIIB } \\
\text { b) Überprüfung des Stellenwertes „biologischer Therapieprinzipien“ } \\
\text { (Metalloproteinaseinhibitoren; Angiogeneseinhibitoren) }\end{array}$ \\
\hline IIIB & $\mathrm{CT} \rightarrow \mathrm{TRT}+\mathrm{PCl}$ (falls CR) & $\begin{array}{l}\mathrm{CT} / \mathrm{TRT}+\mathrm{PCl} \text { (falls CR) } \\
\text { Behandlung in Studien* }\end{array}$ & \\
\hline
\end{tabular}

* Für geeignete Patienten möglichst Teilnahme in Phase-III-Studien mit dem Ziel der Therapieoptimierung. CT: Chemotherapie; TRT: Thorakale Radiotherapie; OP: Operation; PCl: (prophylactic cranial irradiation) adjuvante Ganzschädelbestrahlung; CR: Vollremission

\section{Stadium IV}

Bereits bei Diagnosestellung zeigen $2 / 3$ der Patienten mit einem kleinzelligen Bronchialkarzinom (SCLC) Fernmetastasen (Stadium IV gemäß ISS). Ohne Behandlung liegt die mediane Lebenserwartung für diese Patienten bei 6 Wochen; mit einer Polychemotherapie (Cis- bzw. Carboplatin/Etoposid; Adriamycin bzw. Epirubicin/Cyclophosphamid/Vincristin; Ifosfamid/Etoposid) hingegen bei 6-9 Monaten. Diese ist das zentrale Therapieelement und orientiert sich am Ansprechen der klinischen Symptomatik (Abnahme von Dyspnoe/Husten, Besserung des Allgemeinbefindens). Der palliative Charakter der Behandlung im Stadium IV wird allerdings in der geringen 2-Jahres-Überlebensrate $<5 \%$ deutlich.

Ebenfalls unter palliativen Gesichtspunkten wird die Strahlentherapie bei frakturgefährdeten oder schmerzhaften Skelettmetastasen, Hirnmetastasen, tumorbedingter Rückenmarkkompression oder einer behandlungsbedürfigen Symptomatik als Folge der pulmonalen Tumorausbreitung eingesetzt.

Darüber hinaus wurde in einer randomisierten Studie deutlich, dass mit Erreichen einer Vollremission bzw. einer kompletten Remission der Fernmetastasen kombiniert mit einer partiellen Remission im Bereich des Primärtumors nach 3 Chemotherapiekursen im Stadium IV durch eine zusätzliche lokoregionäre Radiotherapie simultan zur weiteren Chemotherapie im Vergleich zur alleinigen Chemotherapie eine signifikante Verbesserung der medianen Überlebenszeit (17 vs. 11 Monate) wie auch Langzeitüberlebensrate (5-Jahres-Überlebensrate 9\% vs. 4\%) erreicht werden kann [17]. Eine generelle Empfehlung dieses Vorgehens bedarf allerdings weiterer randomisierter Studien.

\section{Stadienabhängige Therapie des nicht-kleinzelligen Bronchialkarzinoms}

Bei ca. 30\% der Patienten mit einem nicht-kleinzelligen Bronchialkarzinom (NSCLC) liegt zum Diagnosezeitpunkt noch ein lokal begrenztes Tumorstadium I oder II vor. Demgegenüber weisen 40\% der Patienten bereits Fernmetastasen auf (Stadium IV). Die verbleibenden $30 \%$ haben lokal fortgeschrittene, aber noch nicht fernmetastasierte Tumoren. Bei den letzteren ist zu bedenken, dass trotz technisch resektabler Tumorausdehnungen die Operation allein oder auch in Kombination mit einer postoperativen Bestrahlung nicht immer zu befriedigenden Langzeitergebnissen führt. So liegen im Stadium IIIA mit präoperativ histologisch gesichertem Befall mediastinaler Lymphknoten die 5-Jahres-Überlebensraten nach Operation und Radiotherapie unter 10\% [18].

\section{Stadium I/II}

Basis für eine kurative Behandlung ist in diesen Stadien die Resektion des Primärtumors mit umfassender mediastinaler Lymphadenektomie. Für das Stadium I werden so 5-Jahres-Überlebensraten (5-Jahres-Überlebensrate) von 60-70\% und für das Stadium II von 40-60\% erreicht [1]. Im Falle der Inoperabilität ist die kurativ intendierte Strahlentherapie etablierter Behandlungsstandard (Tab. 4).

Für die Gruppe der Patienten mit alleiniger Tumorinvasion der Brustwand (T3 NO M0) hat sich die radikale En-bloc-Operation als günstig erwiesen $[19,20]$. Die postoperative Strahlentherapie wird aufgrund klinischer Erfahrungen durchgeführt; Ergebnisse zur Wirksamkeit dieser Strahlentherapie sind durch kontrollierte Studien nicht eindeutig definiert [19]. Insgesamt werden lokale Kontrollraten von 80-90\% und 5-Jahres-Überlebensrate von 30-50\% erreicht [19-21]. Im Falle der Inoperabilität ist auch hier die kurativ intendierte Strahlentherapie etablierter Behandlungsstandard [22]. 
Bei Tumoren mit Infiltration der oberen Thoraxapertur („Pancoast-Tumor") ist die präoperative Strahlentherapie zur Verbesserung der Resektabilität üblich $[23,24]$. Nach R0-Resektion (etwa $60 \%$ ) kann eine 5-Jahres-Überlebensrate von $45 \%$ erreicht werden [25]. In randomisierten Studien wurde dieses Vorgehen bisher nicht geprüft; eine individuelle interdisziplinäre Indikationsstellung wird deshalb empfohlen $[26,27]$.

In der Rezidivsituation nach kurativer Resektion dominieren in den Stadien I/II Fernmetastasen. Isolierte Lokalrezidive sind allenfalls in $10-30 \%$ der Rezidivmanifestationen zu erwarten $[28,29]$. Ferner können bei $30-50 \%$ der Patienten bereits zum Operationszeitpunkt isolierte disseminierte Tumorzellen nachgewiesen werden [30,31]. Dies legt nahe, dass durch eine effektive systemische Kontrolle der Erkrankung eine Prognoseverbesserung erwartet werden kann [32]. Daher wird der mögliche Stellenwert einer adjuvanten oder neoadjuvanten Chemotherapie im Stadium I bzw. II in randomisierten Studien geprüft (Tab.4).

Die PORT-Metaanalyse zeigt, dass eine postoperative Strahlentherapie in den Stadien I und II zu einer Verschlechterung des Überlebens führen kann, so dass in diesen Stadien bei R0-Resektion eine routinemäßige Nachbestrahlung nicht indiziert ist [33]. Kritisch anzumerken ist jedoch, dass die der PORT-Metaanalyse zugrunde liegenden strahlentherapeutischen Techniken heutigen Standards zum größten Teil nicht mehr genügen [34].

\section{Stadium III}

Im Stadium III sind bei kurativem Ansatz die Operation (gegebenenfalls mit nachfolgender Strahlentherapie) und die radikale Strahlentherapie bzw. Chemo-/Radiotherapie etablierte Standardverfahren. Im Stadium IIIA zeigt sich nach kurativer Resektion, dass das Auftreten von Fernmetastasen (in 70-80\% der Rezidivfälle) der wesentliche, die Prognose bestimmende Faktor ist. Diese Patienten könnten von einer neoadjuvanten, d.h. präoperativen Chemotherapie profitieren. Von den Studien, die diesen Therapieansatz im randomisierten Vergleich zur alleinigen Ope- ration prüfen, zeigen zwei kleine mit jeweils 60 Patienten eine signifikante Verlängerung der Überlebenszeiten für die neoadjuvant Behandelten [35,36]. Möglicherweise führt der Einsatz einer präoperativen Radiotherapie zusätzlich zur Chemotherapie zu noch günstigeren Remissions- und Resektionsraten und damit auch Langzeitüberlebensraten und kann zudem auch im Stadium IIIB noch eine Operation ermöglichen [37 - 39]. Der Stellenwert der präoperativen Radiotherapie in der neoadjuvanten multimodalen Behandlung wird derzeit in einer randomisierten Studie geprüft [40].

Für inoperable Patienten mit gutem Allgemeinzustand im Stadium III zeigen drei randomisierte Studien, dass die Sequenz aus Chemotherapie und Radiotherapie signifikant günstigere Überlebensraten als die alleinige Standardradiotherapie erbringt [41 - 46]. Daher wird für solche Patienten diese Therapiesequenz empfohlen (Tab. 4) [47].

Allerdings findet sich auch im sequenziellen Therapieansatz innerhalb eines Jahres eine Rate der lokalen Erkrankungsprogression von $80 \%$ [42]. Daran wird die Bedeutung einer effektiven lokalen Kontrolle für das Überleben deutlich [48]. In randomisierten Studien zeichnen sich hierfür im Vergleich zur alleinigen Radiotherapie Möglichkeiten in Form einer intensivierten, akzelerierthyperfraktionierten Radiotherapie [49] oder einer Verstärkung des Effektes der Radiotherapie durch eine niedrig dosierte simultane Chemotherapie ab [50-52].

Darüber hinaus zeigt, im Vergleich zu dem sequenziellen Therapieansatz, eine randomisierte Studie für eine normal dosierte Chemotherapie (im Abstand von 3-4 Wochen) simultan zur Radiotherapie eine Verbesserung der 5-Jahres-Überlebensrate um $7 \%(8,9 \%$ vs. $15,8 \%)$ [53]. In einer weiteren randomisierten Studie wird dies im Trend bestätigt [54]. Daher kann für inoperable Patienten mit gutem Allgemeinzustand im Stadium III auch ein solch simultaner Ansatz mit normal dosierter Chemotherapie im Abstand von 3-4 Wochen empfohlen werden. Allerdings ist hier mit einem deutlich höheren Maß an Hämatotoxizität wie auch nicht-hämatologischen Toxizitäten zu rechnen. Bei der Pla-

Tab. 4 Nicht-kleinzelliges Bronchialkarzinom: Therapie gemäß Stadium

\begin{tabular}{|c|c|c|c|}
\hline Stadium & $\begin{array}{l}\text { derzeit überwiegend } \\
\text { praktizierte Therapie }\end{array}$ & Empfehlung & $\begin{array}{l}\text { Möglichkeiten zur prognoserelevanten } \\
\text { Verbesserung der Therapie }\end{array}$ \\
\hline IA & $\begin{array}{l}\text { Operation } \\
\text { falls inoperabel: Radiotherapie }\end{array}$ & $\begin{array}{l}\text { Operation } \\
\text { falls inoperabel: Radiotherapie }\end{array}$ & $\begin{array}{l}\text { Neoadjuvante bzw. adjuvante systemische } \\
\text { Therapie. Optimierung der Radiotherapie }\end{array}$ \\
\hline$I B / I I$ & $\begin{array}{l}\text { Operation } \\
\text { falls inoperabel: Radiotherapie }\end{array}$ & Behandlung in Studien* & $\begin{array}{l}\text { Neoadjuvante bzw. adjuvante systemische } \\
\text { Therapie. Optimierung der Radiotherapie }\end{array}$ \\
\hline \multicolumn{4}{|l|}{ III } \\
\hline operabel (zumeist IIIA) & Operation + Radiotherapie & Behandlung in Studien* & Multimodale Konzepte. \\
\hline inoperabel (zumeist IIIB) & Radiotherapie & $\begin{array}{l}\text { Chemotherapie (platinbasiert) } \\
\text { - gefolgt von Radiotherapie } \\
\text { - simultan zur Radiotherapie } \\
\text { bzw. Behandlung in Studien* }\end{array}$ & $\begin{array}{l}\text { Multimodale Konzepte. } \\
\text { Optimierung der Radiotherapie }\end{array}$ \\
\hline IV & $\begin{array}{l}\text { Chemotherapie } \\
\text { palliative Therapie } \\
\text { am „Ort der Not“ }\end{array}$ & $\begin{array}{l}\text { Chemotherapie } \\
\text { bzw. Behandlung in Studien* }\end{array}$ & $\begin{array}{l}\text { Überprüfung neuer Chemotherapie- } \\
\text { kombinationen bzw. Tyrosinkinase-/ } \\
\text { Angiogeneseinhibitoren }\end{array}$ \\
\hline
\end{tabular}

\footnotetext{
* Für geeignete Patienten möglichst Teilnahme in Phase-III-Studien mit dem Ziel der Therapieoptimierung. Insbesondere für die Stadien I- III ist dies zu empfehlen, da hier die Therapiekonzepte im Fluss sind. In ganz besonders hohem Maß ist dies im Stadium III der Fall. So ist z. B. im Stadium IIIA nach Operation + Radiotherapie im besten Fall eine 5-Jahres-Überlebensrate von 20-25\% zu erwarten. Im Rezidiv dominieren in $80 \%$ Fernmetastasen, so dass in Studienkonzepten unter Integration einer systemischen Therapie eine Prognoseverbesserung erwartet werden kann. Daher wird hier eine Therapie außerhalb von Studien auch nur eingeschränkt empfohlen.
} 
nung einer sequenziellen oder simultanen Chemoradiotherapie ist die Auswahl der eingesetzten Zytostatika von besonderer Bedeutung, da z.B. Mitomycin und, bei simultaner Gabe, Gemcitabin mit einem höheren Risiko schwerer Strahlennebenwirkungen verbunden sind. Substanzen wie Cisplatin, Etoposid und Vinorelbine sind in dieser Hinsicht geprüft und weniger kritisch.

Für Patienten, die keine Kandidaten für eine sequenzielle oder simultane Chemoradiotherapie sind, ist die alleinige hochdosierte Strahlenbehandlung die Therapie der Wahl. Die akzeleriert-hyperfraktionierte CHART (Continuous Hyperfractionated Accelerated Radiotherapy)-Bestrahlung konnte in einer randomisierten Studie das 2-Jahres-Überleben gegenüber einer konventionell fraktionierten Strahlentherapie bis 60 Gy von $20 \%$ auf $29 \%$ signifikant verbessern. Diese Behandlung kann in geeigneten Fällen als optimierte Möglichkeit der Bestrahlung angesehen werden [49,55-57]. Ob eine dosiseskalierte Modifikation des CHARTSchemas die Ergebnisse der Bestrahlung weiter steigern kann, wird derzeit in einer randomisierten Studie geprüft [58]. Die alleinige Hyperfraktionierung ohne Akzelerierung hat im randomisierten Vergleich mit einer konventionellen Bestrahlung keinen Vorteil ergeben [44,57]. Der Wert einer Dosiseskalation über 60-70 Gy hinaus unter Einsatz 3D-konformaler Bestrahlungstechniken wird derzeit von mehreren Studiengruppen geprüft.

Zur weiteren Optimierung der Therapiekonzepte im Stadium III sind randomisierte Studien notwendig. Daher ist die Behandlung von Patienten im Rahmen solcher Phase-III-Studien, die auch einen Fortschritt in der Therapieoptimierung erwarten lassen, wünschenswert. Darüber hinaus gewinnt angesichts der Effektivität, aber auch Toxizität solcher Therapieansätze die prätherapeutische Charakterisierung von Patientensubgruppen, die besonders profitieren oder aber denen wegen zu geringer Erfolgsaussicht eine solche Behandlung nicht zugemutet werden sollte, an Bedeutung $[59,60]$.

\section{Stadium IV}

Im randomisierten Vergleich zur bestmöglichen supportiven Behandlung führen cisplatinhaltige zytostatische Kombinationen in diesem Tumorstadium zu einer in Metaanalysen bestätigten signifikanten Verlängerung der medianen Überlebenszeit von 6 auf 8 Monate [61]. Solche Patienten, die auf eine Chemotherapie mit einer partiellen Remission ansprechen (20-30\%), profitieren mit medianen Überlebenszeiten von 12 - 14 Monaten [62]. Insgesamt geben 60\% der mit einer Chemotherapie behandelten Patienten eine Besserung subjektiver Beschwerden wie Schmerzen, Reizhusten oder Hämoptysen an [63,64]. Faktoren, die für einen zytostatischen Behandlungsversuch sprechen, sind das Vorliegen tumorassoziierter Beschwerden oder ein Erkrankungsprogress in einem eng definierten Zeitraum (3 Monate).

Für Patienten mit Fernmetastasen und (a) hinreichendem Allgemeinzustand (Karnofsky-Index $\geq 70$ ) sowie (b) fehlender, eine solche Behandlung ausschließende Komorbidität, werden zwei Zyklen einer Platin-haltigen Polychemotherapie empfohlen (Cisplatin/Etoposid; Cisplatin/Vincaalkaloid; Mitomycin/Ifosfamid/ Cisplatin bzw. Mitomycin/Vincaalkaloid/Cisplatin; Cisplatin/Paclitaxel; Cisplatin/Gemcitabin). Werden die vorgenannten Protokolle bei relevant eingeschränkter Organfunktion (z. B. Nierenin- suffizienz) in Erwägung gezogen, sollte Cisplatin gegen Carboplatin ausgetauscht werden. Im Falle eines Ansprechens (Symptomenreduktion; Tumorverkleinerung über $50 \%$ ) sollte die Chemotherapie auf vier bis sechs Behandlungszyklen ausgedehnt werden. Die Evidenz zur Behandlung von Patienten mit einem Karnofsky-Index $\leq 60$ mit einer Platin-haltigen Polychemotherapie ist eingeschränkt, da in den entsprechenden Studien allenfalls $10-20 \%$ der eingeschlossenen Patienten diesen Allgemeinzustand (ECOG 2 ) hatten.

Bei Patienten (a) in eingeschränktem Allgemeinzustand (Karnofsky-Index $\leq 60$, jedoch so hinreichend, dass zusätzlich zum Nachtschlaf kein weiterer Ruhebedarf von mehr als 6 Stunden pro Tag besteht) oder (b) mit einer eine Platin-haltige Chemotherapie ausschließenden Komorbidität kann eine zytostatische Monotherapie (z.B. Vinroelbin; z. B. Gemcitabin) erwogen werden. Diese Behandlung sollte nur fortgeführt werden, solange sie (a) gut verträglich ist und (b) ein Ansprechen der Erkrankung (Symptomenreduktion) dokumentiert werden kann.

Im Falle einer erneuten Progression der Erkrankung nach Platinhaltiger Vorbehandlung kann bei Patienten in gutem Allgemeinzustand (Karnofsky-Index $\geq 70$ ) eine Zweitlinientherapie (z.B. Docetaxel) erwogen werden.

Bei bronchial okkludierendem Tumorwachstum haben sowohl die kleinvolumige, palliativ intendierte externe Strahlentherapie, die intraluminale Brachytherapie wie auch die endobronchiale Laser- und Stentbehandlung ihren Stellenwert. Die perkutane palliative Strahlentherapie ist zudem bei schmerzhaften und/ oder frakturgefährdeten Skelettmetastasen, Hirnmetastasen, tumorbedingter Rückenmarkkompression oder einer behandlungsbedürftigen Symptomatik im Bereich des Primärtumors indiziert.

\section{Palliative Therapiemaßnahmen}

Für alle im Folgenden dargestellten tumorspezifischen Komplikationen und Präsentationen inklusive ihrer palliativ-therapeutischen Maßnahmen gilt, dass die Therapie der Grundkrankheit bzw. die tumorspezifische Therapie die Basis im Gesamtbehandlungskonzept darstellt.

Skelettmetastasen. Skelettmetastasen, die zu einer Frakturgefahr oder Schmerzsymptomatik führen, erfordern eine palliative Radiotherapie oder eine chirurgische Stabilisierung [65-67] (vgl. Abschnitt: Radiotherapie aus palliativer Indikation). Indikationen für eine primäre chirurgische Versorgung einer Knochenmetastase sind die pathologische Fraktur eines tragenden Knochens, die dadurch erreichbare Besserung einer Immobilität und in Ausnahmefällen die gleichzeitige histologische Diagnosesicherung. Des Weiteren ist die Indikation zur chirurgischen Versorgung bei hochgradiger Frakturgefahr eines tragenden Röhrenknochens bzw. eines Wirbelkörpers zu prüfen. Erwächst angesichts eines hochgradig frakturgefährdeten Wirbelkörpers das Risiko einer drohenden Querschnittssymptomatik ist die Indikation zur operativen Stabilisierung umgehend zu stellen [65]. Der günstige Effekt einer Bisphosphonattherapie auf die Frakturrate 
und auf die Schmerzsymptomatik wurde beim multiplen Myelom und beim Mammakarzinom gezeigt [68 - 70].

Hirnmetastasen. Die Standardtherapie ist die perkutane Ganzhirn-Bestrahlung. Das perifokale Ödem wird erfolgreich mit Dexamethason (Initialdosis z. B. $4 \times 4-8 \mathrm{mg} / \mathrm{die}$ ) behandelt. Durch diese Maßnahmen wird in ca. 70-90\% der Fälle eine signifikante Besserung der neurologischen Symptomatik erzielt $[71,72]$.

Bei Vorliegen einer solitären Hirnmetastase werden hinsichtlich der Verlängerung der medianen Überlebenszeit sowie der lokalen Tumorkontrolle und Symptomenbesserung durch die chirurgische Resektion, gefolgt von einer Ganzhirn-Bestrahlung, signifikant günstigere Ergebnisse, als durch die alleinige Radiotherapie, erreicht $[72,73]$. Daher sollte im Falle einer solitären Hirnmetastase die Stellungnahme eines erfahrenen Neurochirurgen eingeholt werden. Allerdings ist diese bimodale Therapie für weniger als 50\% der Patienten mit solitärer Hirnmetastase geeignet (Inoperabilität aus neurochirurgischer Sicht aufgrund der Metastasenlokalisation; im Hirn singuläre Metastase, jedoch weitere sonstige Metastasen) [72,73]. Möglicherweise ist dann die stereotaktische Radiochirurgie eine sinnvolle Alternative zur chirurgischen Resektion bei solitärer Hirnmetastasierung $[74,75]$.

Vena-cava-superior-Syndrom (VCSS). Dem VCSS, bedingt durch eine Kompression, Infiltration oder Thrombosierung der V.cava superior mit Behinderung des Blutabstromes aus den oberen Körperpartien, liegt in über $80 \%$ der Fälle ein maligner Tumor zugrunde [76]. Ein akut auftretendes VCSS stellt einen onkologischen Notfall dar. Vor jeder therapeutischen Intervention sollte der Versuch der histologischen Diagnosesicherung unternommen werden $[77,78]$. Allerdings darf dies nicht zu einer Verzögerung der dringend notwendigen Behandlung führen. Eine Antikoagulation mit niedrig-dosiertem Heparin sollte umgehend eingeleitet werden. Beim NSCLC ist die perkutane Radiatio, beim SCLC die systemische Chemotherapie oder ebenfalls die Radiatio die jeweilige Standardtherapie mit in der Regel guten $\mathrm{Er}$ folgsaussichten und Rückbildung der Symptomatik innerhalb von 3-5 Tagen. Bei tumorbedingter Kompression ohne Thrombenbildung kann eine rasche Beschwerdeminderung durch perkutane Angioplastieverfahren wie Ballondilatation mit Stent-Implantation erzielt werden [79,78]. Die chirurgische Behandlung des VCSS ist in ausgewählten Fällen möglich [80].

Thoraxwandmetastase. Im Falle einer isolierten Thoraxwandmetastase ist die chirurgische Resektion Therapie der Wahl. Ist die chirurgische Therapie nicht möglich, ist, insbesondere bei medikamentös nicht zu beherrschenden Lokalschmerzen die perkutane Radiotherapie - beim SCLC eventuell in Kombination mit einer zytostatischen Chemotherapie - das zu empfehlende Therapieverfahren (vgl. Abschnitt: Radiotherapie aus palliativer Indikation).

Rückenmarkkompression. Die drohende Querschnittslähmung infolge einer Infiltration des Spinalkanals oder eine Wirbelkörperkompression ist ein onkologischer Notfall. In $70 \%$ der Fälle liegt die Kompression im thorakalen, in 20\% der Fälle im lumbalen und in $10 \%$ der Fälle im zervikalen WS-Bereich [81]. Als Sofortmaßnahme wird eine antiödematöse Therapie mit hochdosiertem Dexamethason durchgeführt $(40-100 \mathrm{mg} / \mathrm{d}$; in der einzigen randomisierten Studie zum Stellenwert von Steroiden in dieser Situation wurden 96 mg Dexamethason geprüft [82]). Da der Erhalt der neurologischen Funktionen wesentlich vom Schweregrad der Ausfälle und vom Zeitintervall zwischen Beginn und Therapiebeginn abhängt, ist die umgehende Einleitung einer Operation oder einer palliativen perkutanen Radiatio das Standardtherapieverfahren [67]. Im Falle eines SCLC mit ausgedehnter lokaler Tumorausbreitung kann eine zytostatische Chemotherapie indiziert sein.

Chirurgische Interventionen, gefolgt von einer perkutanen Radiatio, gewinnen an Bedeutung [83]. Eine chirurgische Intervention kann z. B. bei knöcherner Kompression, bei statischer Instabilität, bei Progress während Strahlentherapie, bei der Notwendigkeit zur histologischen Diagnosesicherung, bei plötzlich progredienten neurologischen Ausfällen, einem bestrahlungsresistenten Primärtumor oder bei einer Tumorausbreitung im vorbestrahlten Areal indiziert sein [84]. Bei einer intraspinalen Metastase oder Infiltration des Spinalkanales ist eine Laminektomie indiziert. Bei metastatischem Befall eines Wirbelkörpers ist die Ausräumung des Wirbelkörpers mit anschließender Wirbelkörperersatzoperation einschließlich von Verbundosteosynthesen erforderlich. Grundsätzlich sollte das therapeutische Vorgehen interdisziplinär zwischen Neurochirurgen, Wirbelsäulenchirurgen und Radioonkologen abgestimmt werden. Bei frühzeitiger therapeutischer Intervention wird in der überwiegenden Zahl einer tumorbedingten spinalen Kompression eine gute Palliation erzielt [86]. Liegt bei Therapieeinleitung bereits eine Einschränkung der Gehfähigkeit oder eine Paraplegie vor, sinkt die Chance auf Erhalt bzw. Wiederherstellung der Gehfähigkeit auf etwa $60 \%$ bzw. $10 \%$ [85].

Pleuraerguss. Der maligne Pleuraerguss wird insbesondere bei Auftreten typischer Symptome wie Dyspnoe als Folge der Kompression vitalen Lungengewebes, Husten oder Thoraxschmerzen therapiebedürftig. Die Sonografie ist für den Nachweis und die Lokalisation eines Pleuraergusses die sensitivste Methode. Die Therapie der Wahl ist die Thorakozentese und Entlastung der Pleurahöhle von maximal $2000 \mathrm{ml}$ Flüssigkeit pro Tag (bei gröBeren Volumina besteht die Gefahr eines unilateralen Lungenödems als Reexpansionsphänomen). Bei rascher Neubildung des Pleuraergusses und fortbestehender klinischer Symptomatik ist die Anlage einer Pleuradrainage und der Versuch der Pleurodese durch Instillation lokal sklerosierender Substanzen indiziert. Das wirksamste Pleurodese-Verfahren mit einer Erfolgsquote von $75-100 \%$ ist die thorakoskopische Applikation von Talkum-Puder $[87,88]$. Alternativ kann mit geringeren Erfolgsaussichten die Instillation einer Talkum-Emulsion über einen doppellumigen Drainageschlauch erfolgen. Erfolgsraten von $50-80 \%$ werden für Tetrazyklin (500 - $1000 \mathrm{mg}$, max. $20 \mathrm{mg} / \mathrm{kg} \mathrm{KG),} \mathrm{Bleomy-}$ cin $(60 \mathrm{mg})$, Mitoxantron $(30 \mathrm{mg})$ und ggf. Fibrinkleber beschrieben $[89,88]$. Es ist zu beachten, dass die medikamentöse Pleurodese wegen des Verdünnungseffektes bei noch vorhandenem Resterguss nur bei vollständig entleerter Pleurahöhle versucht werden kann. Bleibt die Pleurodese trotz dieser Maßnahmen erfolglos, kann, in Abhängigkeit vom Allgemeinzustand des Patienten, auch eine chirurgische Intervention zur Pleurektomie sinnvoll sein [90]. Bei einer „gefesselten“ Lunge, z. B. durch ausgedehnten Tumorbefall der viszeralen Pleura ober bei persistierender bronchopleuraler Fistel, ist die Drainage-Therapie nicht erfolgreich. In diesem Fall kann, in Abhängigkeit vom Allgemeinzu- 
stand des Patienten, eine Pleurektomie, kombiniert mit einer viszeralen Dekortikation der Lunge, erfolgen.

Perikarderguss. Das Spektrum der klinischen Präsentation des malignen Pleuraergusses reicht von fehlender Symptomatik bis zur akuten Herztamponade. Die Perikardiozentese wird sowohl aus diagnostischen als auch aus therapeutischen Gründen durchgeführt. Zur Prävention des Perikardergussrezidivs stehen prinzipiell die gleichen Sklerosierungssubstanzen wie beim malignen Pleuraerguss zur Verfügung. Über die Perikardiozentese hinausgehende mechanische bzw. chirurgische Interventionen wie Perikardiotomie oder Perikardektomie gewinnen hauptsächlich bei Versagen der Sklerosierungsverfahren an Bedeutung [91].

Schmerzen. Chronische Schmerzzustände bei Tumorpatienten sind in ca. 70\% der Fälle durch den Primärtumor oder seine Metastasen bedingt. In $15 \%$ der Fälle treten die Schmerzen als Folge einer antiproliferativen Therapie auf (z. B. Zytostatika-induzierte Polyneuropathie), in 5\% sind sie tumorassoziiert (z.B. Pleuraerguss oder Aszites) und in $10 \%$ der Fälle stehen die Schmerzen in keinem Zusammenhang mit der Tumorkrankheit (z. B. degenerative Gelenkerkrankungen, Migräne) [92]. Das Prinzip der Therapie des chronischen Tumorschmerzes beruht auf der regelmäßigen Applikation von Analgetika. Zur Pharmakotherapie wurde von der WHO [93] ein Stufenplan entwickelt, welcher Medikamentengruppen ordnet und Anhaltspunkte für sinnvolle Kombinationen gibt. Durch die Gabe des Analgetikums in regelmäßigen, der jeweiligen Wirkdauer des Präparates angepassten Zeitintervallen sollen Schmerzdurchbrüche vermieden werden. Je nach Schmerzart und weiteren gleichzeitig bestehenden Symptomen werden zusätzlich Spasmolytika, Antiemetika, Anxiolytika und Antidepressiva eingesetzt. Bei Umsetzung der WHOEmpfehlungen sind ca. 90\% aller Patienten mit Tumorschmerzen zufriedenstellend zu behandeln [94].

$\mathrm{Zu}$ prüfen ist immer, ob durch eine palliative perkutane Bestrahlung z. B. bei Knochenmetastasen oder Thoraxwandinfiltrationen der Schmerz ursächlich behandelt werden kann. Eine Bestrahlung schmerzhafter ossärer Metastasen führt in etwa 75\% der Fälle zur Schmerzreduktion und bei jedem zweiten Patienten zur Schmerzlosigkeit [95]. Lokale, invasive Analgesieformen wie z.B. Chordotomie oder Neurolyse können im Einzelfall hilfreich sein. Dies gilt auch für die Schmerztherapie von multiplen Knochenmetastasen mit Radiopharmazeutika wie Sr-89, Re-186, Sm-153 [66].

Hyperkalzämie. Diese Elektrolytstörung tritt als Folge einer ossären Metastasierung oder im Rahmen einer Paraneoplasie auf. Bei Kalziumkonzentrationen $>3 \mathrm{mmol} / \mathrm{l}$ besteht die Basistherapie aus einer forcierten $\mathrm{NaCl}$-Diurese (z. B. 4-61 NaCl 0,9\%, Furosemid $20 \mathrm{mg}$ alle $4-6 \mathrm{~h}$ entsprechend ZVD und Ausscheidung) und einer Glukokortikoid-Therapie (z.B. $100 \mathrm{mg}$ Prednisolonäquivalent i.v.) bis zur Normalisierung der Kalziumkonzentration. Bisphosphonate (z.B. Clodronat $5 \mathrm{mg} / \mathrm{kg} \mathrm{KG}$ täglich für 3-5 Tage oder Pamidronat 60-90 mg über 4-6h am Tag 1) sind wirksame Therapeutika zur Senkung der erhöhten Kalziumkonzentration mit einem maximalen Effekt zwischen Tag 3 und 6. Wegen der guten Verträglichkeit und Wirksamkeit dieser erwähnten Therapieverfahren wird Calcitonin nur noch selten eingesetzt.
Hämoptysen. Intermittierend auftretende, geringgradige Hämoptysen als Folge von Schleimhautblutungen oder Blutungen aus der Tumoroberfläche bedürfen in der Regel keiner Therapie. Bei stärkeren Blutungen aus der Tumoroberfläche lässt sich mit endoskopischen Koagulationsverfahren meistens eine ausreichende Blutstillung erreichen. Geeignet ist entweder ein $\mathrm{Nd}$ YAG-Laser, ein Elektrokauter oder ein Argonplasmakoagulator (APK). Der APK wirkt im Vergleich zum Laser nur sehr oberflächlich, ist aber praktikabler, wenn die Blutungsquelle nicht genau lokalisiert werden kann [96]. Eine perkutane palliative Bestrahlung führt in mehr als der Hälfte der Patienten zum Verschwinden von Hämoptysen $[97,98]$. Eine endobronchiale Brachytherapie ist ebenfalls innerhalb weniger Tage hämostyptisch wirksam [99]. Bei weiter peripher lokalisierten Blutungsquellen kann temporär ein Bronchusblocker eingelegt werden [100], um Zeit für eine Bronchialarteriografie mit Embolisation [101,102] oder eine Operation zu gewinnen.

Husten. Bei chronischem quälenden Husten sollte auch geprüft werden, ob eine Erfordernis zur bronchologischen Intervention, z. B. bei stenosierendem Tumor im zentralen Bronchialsystem, gegeben ist. Bei solchen Patienten führt eine perkutane palliative Strahlentherapie in etwa 50\% zur Minderung der Symptome $[97,98]$. Ist die Ursache auf diese Weise nicht zu beheben, besteht die Indikation zur antitussiven Therapie mit Opioiden. Auch systemische Glukokortikoide können zur Linderung beitragen.

Dyspnoe. Bei durch Sauerstoffapplikation therapierbarer Dyspnoe oder respiratorischer Insuffizienz mit $\mathrm{PaO}_{2}$-Werten $<55 \mathrm{mmHg}$ besteht die Indikation zur kontinuierlichen Sauerstoffapplikation via Nasensonde. Eine ausgeprägte Dyspnoe und eine Tachypnoe lassen sich wirkungsvoll mit Opioiden behandeln. Bei Kompression der Atemwege durch den Tumor bzw. durch Lymphknoten kann durch eine palliative perkutane Strahlentherapie bei etwa der Hälfte der Patienten eine Symptomminderung erreicht werden [98]. Liegt der Dyspnoe eine Tumorobstruktion zugrunde, kann durch endoskopische Maßnahmen eine Besserung erreicht werden.

Vorrangiges Ziel ist die Verbesserung der Lebensqualität mit möglichst kurzer Hospitalisierung des Patienten. Prinzipielle Empfehlungen zur Durchführung der einzelnen Maßnahmen wurden von der Deutschen Gesellschaft für Pneumologie erarbeitet [103]:

- Exophytisch wachsende Tumoren in der Trachea und den großen Bronchien kann man endoskopisch verkleinern oder abtragen. Neben der mechanischen Abtragung mit dem starren Bronchoskop (coring out) [104] haben sich verschiedene Verfahren mit gleichzeitiger Blutstillung bewährt (vgl. Abb.1). Am gezieltesten arbeitet man mit dem Nd-YAG-Laser. In 75\% der Fälle ist endoskopisch und klinisch eine Verbesserung zu erwarten [105]. Patienten, bei denen eine Wiedereröffnung gelingt, leben beschwerdefreier und im Mittel 4 Monate länger [106]. Die Kryotherapie [107], die Elektrokoagulation $[108,109]$ und die APK $[96,109]$ sind alternative Methoden mit vergleichbarer Effektivität im Hinblick auf Symptomenlinderung und Lebenszeitverlängerung $[96,107,110]$. Die photodynamische Therapie (PDT) exophytischer Tumore ist vergleichsweise aufwendig und teuer; zudem sind die Patienten durch eine allgemeine Photosensibilität beeinträchtigt und 
der Wirkungseintritt (Lumengewinn) ist verzögert [111]. Wegen der relativen Selektivität für Tumorgewebe kann die PDT auch in kritischen postoperativen Situationen nach multimodaler Vorbehandlung eingesetzt werden [112]. Alle vorgenannten Interventionen können mit dem Fieberbronchoskop durchgeführt werden. Schneller und sicherer und mit einer signifikant niedrigeren Interventionsfrequenz [113] verbunden sind diese Maßnahmen mit dem starren Instrumentarium in Allgemeinanästhesie.

- Bei vorwiegend intramuralem Wachstum nicht-kleinzelliger Karzinome und zur Stabilisierung des Rekanalisationserfolges ist die Brachytherapie, in Form der Kurzzeitbehandlung mit Iridium-192, das Verfahren der Wahl (vgl. Abb.1). Hierbei sind eine Reihe unterschiedlicher Dosis-Bezugs-Systeme und verschiedene Fraktionierungsschemata etabliert $[99,114,115]$. Bei palliativ intendierter Bestrahlung eines okkludierenden Tumorwachstums der zentralen Atemwege kann, im Vergleich zur alleinigen externen Radiotherapie, ein zusätzlicher Boost mit endoluminaler Kleinraumbestrahlung den Effekt verbessern [116].

- Dominiert die extrabronchiale Obstruktion oder liegt eine weitgehende Wandzerstörung vor, besteht die Indikation zur Stenteinlage (vgl. Abb.1). Für die Tumortherapie kommen nur Silikonstents oder ummantelte Metallgitterstents infrage [117]. Durch eine Stenteinlage kann eine sofortige Linderung der Dyspnoe erreicht werden. Auch Patienten mit terminaler Tumorerkrankung können von dieser Maßnahme profitieren [118]. Durch strahlentherapeutische Maßnahmen kann versucht werden, diesen Effekt zu stabilisieren.

\section{Therapiemodalitäten}

\section{Chirurgische Therapie}

\section{Funktionelle Voraussetzungen}

Die Durchführung einer chirurgischen Resektion ist an bestimmte funktionelle Voraussetzungen gebunden (vgl. „Empfehlungen zur Diagnostik des Bronchialkarzinoms“ der Deutschen Gesellschaft für Pneumologie [2]). Am ehesten ist eine optimale chirurgische Therapie und perioperative Betreuung von Patienten mit Bronchialkarzinomen in entsprechend qualifizierten Zentren gewährleistet [119].

\section{Operationsverfahren}

Bei peripheren Tumoren (T1, T2) stellt die Lobektomie mit systematischer mediastinaler Lymphknotendissektion den Standardeingriff dar, der mit einer Letalität von 1-4\% belastet ist $[120,121]$. Atypische Resektionen sind mit einer signifikant erhöhten Lokalrezidivrate assoziiert und werden daher nur in palliativer Indikation durchgeführt [122]. Bei zentralem oder lappenüberschreitendem Sitz ist eine Pneumonektomie bzw. rechtsseitig eine obere oder untere Bilobektomie erforderlich. Die Operationsletalität der einfachen Pneumonektomie liegt bei 4-6\% und steigt bei Erweiterung des Eingriffes sowie in höherem Lebensalter und Vorliegen von Komorbiditäten an $[120,123,124]$. Die funktionell ungünstigen Folgen einer Pneumonektomie lassen sich ohne Kompromisse in der Radikalität
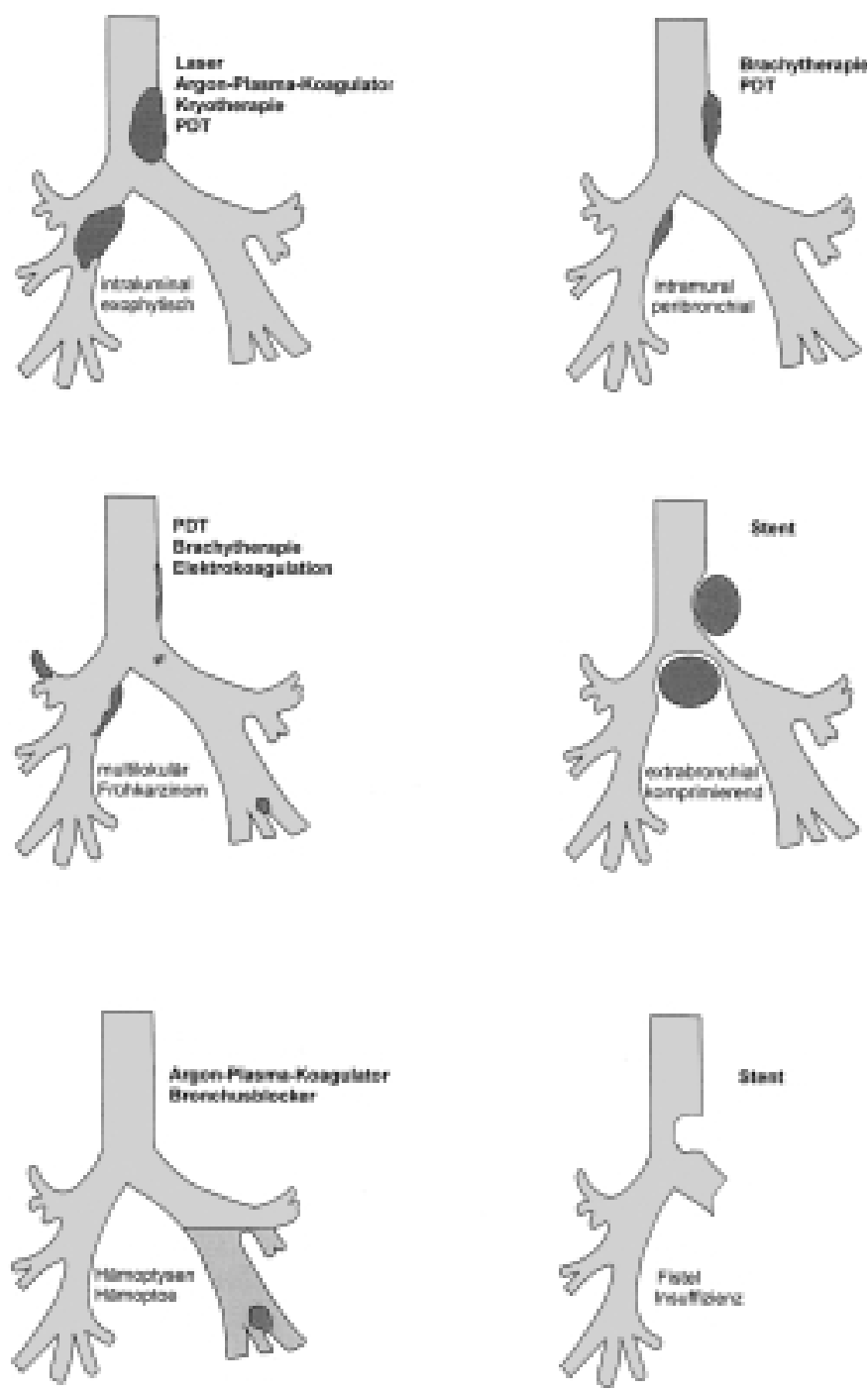

Abb. 1 Maßnahmen der endobronchialen Intervention in Abhängigkeit von der Tumormanifestation.

durch bronchoplastische Verfahren (Sleeve- oder Manschettenresektion), ggf. in Kombination mit angioplastischen Eingriffen, vermeiden [125]. Intraoperativ ist die Schnellschnittuntersuchung der Resektionsgrenzen obligat. In thoraxchirurgischen Zentren liegt die Letalität der aufgeführten Eingriffe im unteren Bereich der angegebenen Spannweiten (Pneumonektomie 4\%; Lobektomie $1 \%$ ). Zudem wurde gezeigt, dass in Zentren, die häufig solche Eingriffe durchführen, die postoperativen Komplikationsraten niedriger und die Überlebensraten höher sind als in Kliniken, in denen nur sporadisch Lungenresektionen erfolgen [126].

Die Weiterentwicklung der Video-Thorakoskopie erlaubt inzwischen unter günstigen Verhältnissen und mit ausreichender Sicherheit Lappenresektionen. Allerdings ist die Wahrung der onkologischen Prinzipien bei der Lymphadenektomie technisch schwierig. Aus diesem Grund wird die videoassistierte thorakoskopische Lappenresektion einschließlich systematischer Lymphknotendissektion auch im Frühstadium kontrovers diskutiert [127-130]. Das Verfahren hat sich dagegen zur Abklärung peripherer Lungenherde bewährt [131]. Sofern sich in der Schnellschnittdiagnostik ein Bronchialkarzinom herausstellt, 
wird die Standardresektion als offene Thorakotomie angeschlossen.

Um eine Eröffnung des Tumors im Situs zu vermeiden, sind sogenannte erweiterte Eingriffe notwendig, wenn der Lunge benachbarte Strukturen per continuitatem infiltriert sind (T3, T4) oder wenn eng benachbarte Strukturen reseziert werden müssen. Bei ausgedehnten Thoraxwandresektionen ist eine Rekonstruktion der Brustwand zur Vermeidung einer paradoxen Atmung oder auch zum mechanischen Schutz der Mediastinalorgane erforderlich. Größere Perikarddefekte, insbesondere nach Pneumonektomien, müssen plastisch gedeckt werden, um einer Herzluxation vorzubeugen. Nach Zwerchfellresektionen ist ein luft- und wasserdichter Abschluss zwischen Pleura- und Peritonealhöhle erforderlich. Schließlich beinhalten erweiterte Eingriffe auch die gelegentlich erforderliche tangentiale oder Kontinuitätsresektion der V. cava superior, Resektionen im Tracheal- und Bifurkationsbereich (Karinaplastik) oder eine simultane Ösophagektomie. Im Einzelfall kann selbst eine En-bloc-Resektion der Aorta thoracica und des Ösophagus sinnvoll sein, wenn dadurch in einer T4 NO-Situation eine R0-Resektion erreicht wird. Wird ein Eingriff mit einer inkompletten Resektion abgeschlossen, ist grundsätzlich die Indikation zur Nachresektion zu prüfen.

Die hiläre und mediastinale Lymphknotendissektion wird unabhängig von der Art des Resektionsverfahrens standardmäßig möglichst en-bloc durchgeführt. Bei einer rechtsseitigen Thorakotomie sollten die hoch- (Level2) und tief- (Level 4) paratrachealen Lymphknoten, die subkarinalen (Level 7) Lymphknoten, sowie die tief mediastinalen (Level 8 und 9) Lymphknoten reseziert werden. Bei einer linksseitigen Thorakotomie sollte die Lymphadenektomie die Stationen tief-paratracheal (Level4), subaortal (Level5), paraaortal (Level6), sowie subkarinal (Level 7) und tief-mediastinal (Level 8 und 9) beinhalten. Die hochparatracheal gelegenen linksseitigen Lymphknoten (Level2) sollten möglichst bereits durch eine präoperative Mediastinoskopie abgeklärt sein, so dass auf eine Mobilisation des Aortenbogens verzichtet werden kann (Bezeichnung der Lymphknotenstationen nach Mountain und Dresler [132]). Die entnommenen Lymphknoten sollten entsprechend ihrer Lokalisation exakt bezeichnet in ein Dokumentationsblatt eingetragen werden [133]. Nur die exakte topographische Zuordnung und die quantitative Erfassung des Anteils befallener Lymphknoten ermöglicht ein präzises und prognostisch aussagekräftiges Lymphknoten-Staging (vgl. „Empfehlungen zur Diagnostik des Bronchialkarzinoms“ der Deutschen Gesellschaft für Pneumologie [2]). Inwieweit eine systematische mediastinale Lymphadenektomie zur Verbesserung der Prognose beiträgt, ist gegenwärtig nicht eindeutig gesichert [134]. Es gibt jedoch Hinweise, dass Patienten mit einem limitierten mediastinalen Lymphknotenbefall von einer ausgedehnten Lymphadenektomie ohne signifikante Zunahme der Häufigkeit perioperativer Komplikationen profitieren $[135,136]$.

\section{Nicht-kleinzelliges Bronchialkarzinom}

Für die kurative Behandlung eines nicht-kleinzelligen Bronchialkarzinoms ist die komplette Tumorentfernung von zentraler Bedeutung. Bei der Mehrzahl der Patienten liegen jedoch zum Diagnosezeitpunkt Fernmetastasen oder fortgeschrittene Tumorstadien mit lokaler Inoperabilität vor. Letztlich kommt die kurative Resektion bei etwa 30\% der Erkrankten infrage, wobei die Stadien IA-IIB die günstigsten Voraussetzungen für eine komplette Tumorentfernung bieten. Im Stadium IV sind in der Regel lediglich palliative Eingriffe möglich. Eine Ausnahme stellen allenfalls Patienten mit isolierten Hirn- oder Nebennierenmetastasen dar, bei denen im Einzelfall nach sequenzieller oder simultaner Metastasektomie die Resektion des Primärtumors angezeigt ist [137-139].

Das Stadium III umfasst prognostisch sehr unterschiedliche Formen der lokal fortgeschrittenen Tumorausbreitung. Bei einer karinanahen Lokalisation, einem hilusnahen Befall der Gefäße, einer Infiltration des Vorhofes oder Infiltration benachbarter Organe können potenziell kurative Eingriffe in Form einer erweiterten Resektion noch möglich sein, sofern eine komplette Resektion gelingt. Die Prognose wird dabei wesentlich vom Lymphknotenstatus und weniger von der T-Kategorie bestimmt [140-142]. Es muss individuell geprüft werden, ob ein N3-Lymphknotenbefall einer kurativen Resektion zugeführt werden kann oder ob andere alternative Therapieverfahren angewendet werden müssen. Während bei kontralateralem mediastinalen Lymphknoten-Befall (N3, Stadium IIIB) technisch durchführbare Eingriffe in der Regel prognostisch nicht sinnvoll sind, wird auch der Erfolg der chirurgischen Therapie im Stadium IIIA (N2) im Wesentlichen von der Ausdehnung des mediastinalen Lymphknotenbefalls bestimmt [143].

\section{Kleinzelliges Bronchialkarzinom}

Zum Zeitpunkt der Diagnosestellung liegt bei Patienten mit kleinzelligen Bronchialkarzinomen meist ein fortgeschrittenes Tumorstadium vor, so dass operative Eingriffe ausgeschlossen sind. Im Stadium I - II hingegen wird die Diagnose auch im Rahmen der diagnostischen Resektion eines peripheren Rundherdes gestellt [144]. Dann erfolgt die Resektion von Tumor und Lymphknoten nach onkologischen Gesichtspunkten, gefolgt von einer Kombinationschemotherapie. Auch nach primärer Chemotherapie mit nachfolgender chirurgischer Resektion werden im Stadium I- IIIA gute lokale Kontrollraten und Langzeitüberlebensraten erreicht $[13,14,145]$. Angesichts einer Rate der lokalen Tumorprogression von etwa $50 \%$ nach einer Sequenz aus Chemound Radiotherapie [146] und von ca. $30 \%$ selbst nach hyperfraktionierter Radiotherapie simultan zur Chemotherapie [11], stellt sich die Frage nach dem Stellenwert der Operation zur Verbesserung der lokalen Tumorkontrolle. Klinische Studien der 70er und 80er Jahre, die jedoch aufgrund ihres Designs nur eine begrenzte Aussagekraft haben [147-149], haben zu einer Zurückhaltung hinsichtlich der Operation im Stadium I- IIIA beigetragen. Eine solche Zurückhaltung scheint jedoch aufgrund der ermutigenden Ergebnisse verschiedener Zentren nicht gerechtfertigt $[16,150,151]$. Nach multimodaler Therapie einschließlich der Operation können 5-Jahres-Überlebensraten von 46\% nach R0-Resektion in Stadium I - IIIB erreicht werden [151]. Eine randomisierte Studie, die den Stellenwert der Operation im multimodalen Therapiekonzept erneut prüft, ist daher wünschenswert.

\section{Chirurgische Maßnahmen aus palliativer Indikation}

Unabhängig vom Stadium der Erkrankung oder der Histologie des Primärtumors kann die Indikation zur palliativen Resektion bei Tumorzerfall mit zentraler Nekrose und Aspirationsgefahr oder bei anderweitig nicht beherrschbarer Tumorblutung bestehen. Weiterhin kann eine Operation bei tumorbedingter Atelek- 
tase mit Abszedierung oder bei Schmerzen infolge einer Thoraxwandinfiltration sinnvoll sein. Die Frage der chirurgischen Therapie unter palliativen Gesichtspunkten sollte frühzeitig gestellt werden, noch bevor strahlentherapeutische oder sonstige Maßnahmen durchgeführt werden. Durch Fortschritte auf dem Gebiet der interventionellen Bronchoskopie (Laser, Stent, endoluminale Bestrahlung) sind palliative chirurgische Eingriffe selten geworden.

\section{Radiotherapie}

\section{Therapieplanung und Applikation}

Bei einer kurativ intendierten Strahlentherapie bzw. Chemoradiotherapie ist heute eine CT-gestützte Bestrahlungsplanung, eine Kontrolle des Plans am Therapiesimulator, der Einsatz sekundärer Kollimatoren und die Bestrahlung am Linearbeschleuniger Standard. Eine 3D-konformale Strahlentherapie bietet wesentliche Vorteile bei der Definition der Zielvolumina und der Schonung von Risikoorganen und ist als Standard zu empfehlen $[152,42]$. In der Palliativtherapie können auch einfachere Bestrahlungstechniken und Telekobaltgeräte zum Einsatz kommen.

\section{Funktionelle Voraussetzungen}

Für eine kurative Strahlentherapie gelten ähnliche funktionelle Voraussetzungen wie für eine chirurgische Resektion [2]. Das Risiko einer klinisch relevanten Pneumonitis bzw. Fibrose korreliert mit dem Lungenvolumen, das bei konventionell fraktionierter Bestrahlung mit mehr als $20-30$ Gy belastet wird ( $V_{20}$ bzw. $V_{30}$ ) [153,154]. Ein weiterer sinnvoller Parameter ist die mittlere Lungendosis. Diese Werte können bei 3D-Planung vor Therapiebeginn aus den Dosis-Volumen-Histogrammen bestimmt werden. Als einfacher singulärer Parameter zur Abschätzung des Risikos kann das $\mathrm{V}_{25}$ empfohlen werden [155]. Bei prätherapeutisch ausreichender Lungenfunktion $\left(\mathrm{FEV}_{1}\right.$ und $\mathrm{DL}_{\mathrm{CO}}>70 \%$ des Sollwerts) sollte das $\mathrm{V}_{25}$ im Regelfall unter $30 \%$ des Gesamtlungenvolumens liegen [155]. In Zweifelsfällen kann eine genauere Abschätzung des posttherapeutisch verbleibenden funktionellen Lungenvolumes unter Berücksichtigung der Lungenperfusionsszintigraphie erfolgen.

\section{Kleinzelliges Bronchialkarzinom}

In Krankheitsstadien ohne Fernmetastasen wird durch die Sequenz Chemotherapie - lokoregionäre Strahlentherapie die Lokalrezidivrate signifikant gesenkt und die Gesamtüberlebensrate signifikant verbessert $[3,4]$. Randomisierte Studien belegen darüber hinaus, dass mit dem frühzeitigen Einsatz der Radiotherapie simultan zur Chemotherapie die Gesamtüberlebensrate noch weiter gesteigert werden kann (5-Jahres-Überlebensraten $20-30 \%$ ) [5-7]. Da im Vergleich zur sequenziellen Therapie in höherem Maß Toxizitäten auftreten, sollte vor Einleiten einer solchen Behandlung beachtet werden, dass Komorbiditäten und Allgemeinzustand auch diese Behandlung ermöglichen.

Die Festlegung des optimalen Zielvolumens, der optimalen Strahlendosis und des optimalen Fraktionierungsschemas der Radiotherapie sind im Fluss [156]. Bei konventionell fraktionierter Strahlentherapie (1,8-2,0 Gy per Fraktion, 5 Fraktionen pro Woche) sollte die Gesamtdosis mindestens $45 \mathrm{~Gy}$ betragen. Auf- grund der nach wie vor hohen Lokalrezidivraten sind bei entsprechender Therapieplanung im sequenziellen Therapieansatz auch Dosen zwischen 50 und 66 Gy gebräuchlich (zumeist im Sinne einer Shrinking-field-Technik appliziert). Eine Bestrahlung der ipsilateralen supraklavikulären Lymphknoten kann bei Tumorsitz im Oberlappen und bei hochmediastinalem Lymphknotenbefall sinnvoll sein.

In einer randomisierten Studie mit früher Radiotherapie, simultan zum 1.Zyklus der Chemotherapie, ist im Vergleich zur konventionellen Fraktionierung eine signifikante Verbesserung des Überlebens für eine beschleunigte, akzeleriert-hyperfraktionierte Strahlentherapie gezeigt worden [11]. Die akzelerierte Hyperfraktionierung ist derzeit noch nicht als Standard etabliert, kann aber im Rahmen kontrollierter klinischer Studien zur Therapieoptimierung bzw. in begründeten Einzelfällen empfohlen werden.

Nach Erreichen einer kompletten Remission ist eine adjuvante Ganzschädelbestrahlung indiziert [12]. Zur Vermeidung von Spätnebenwirkungen sollten niedrige Einzeldosen von 2,0 Gy pro Tag $5 \times$ pro Woche bis zu einer Gesamtdosis von 30 Gy appliziert werden.

Im Stadium I/II ist der Stellenwert der Strahlentherapie nach Operation und Chemotherapie nicht gesichert. Nach chirurgischer Resektion ist außerhalb von Studien eine Indikation zur Strahlentherapie im Falle einer inkompletten Resektion oder einer pN2-Situation gegeben. Wird die Indikation zur konsolidierenden Mediastinalbestrahlung gestellt, so sollten nach einer R0-Resektion mindestens 45 Gy (1,8 - 2,0 Gy pro Fraktion, 5 Fraktionen pro Woche) appliziert werden. Im Falle einer inkompletten Resektion (R1/R2) ist eine Boostbestrahlung zu erwägen. Bezüglich der prophylaktischen Ganzschädelbestrahlung gelten die gleichen Empfehlungen wie vorstehend.

\section{Nicht-kleinzelliges Bronchialkarzinom}

Bei inoperablen Patienten ohne Fernmetastasen wird bei kurativer Zielsetzung und gutem Allgemeinzustand eine Therapiesequenz aus 2-3 Zyklen einer platinhaltigen Chemotherapie und nachfolgender Radiotherapie empfohlen (Tab.4) [41,157]. Im Vergleich zu diesem sequenziellen Ansatz kann ein simultanes Therapiekonzept mit einer konventionellen nicht-dosisreduzierten Chemotherapie (im Abstand von 3-4 Wochen) zeitgleich zur Radiotherapie zu noch günstigeren Überlebensraten führen $[47,48]$. Allerdings ist hier mit einem deutlich höheren Maß an Hämotoxizität zu rechnen.

Standard der Radiotherapie ist eine Zielvolumendosis von 60 bis 70 Gy in konventioneller Fraktionierung (in aller Regel unter Einsatz einer „Shrinking-field“-Technik) [51,158]. In der Regel werden die mediastinalen Lymphknoten adjuvant bis $50 \mathrm{~Gy}$ bestrahlt, danach erfolgt eine Boostbestrahlung auf den Primärtumor und der gemäß den Kriterien der bildgebenden Diagnostik befallenen Lymphknoten. Eine adjuvante Bestrahlung der ipsilateralen supraklavikulären Lymphknoten kann bei Oberlappentumoren oder bei Lymphknotenbefall im oberen Mediastinum erwogen werden.

Im Falle einer eingeschränkten Lungenfunktion sowie bei kleinen Tumoren und cNO-Situation kann individuell eine kleinvolu- 
mige Bestrahlung allein des Primärtumors erwogen werden [152].

Für Patienten, die keine Chemoradiotherapie erhalten, aber bei denen dennoch ein kurativer Therapieansatz besteht, ist eine hochdosierte alleinige Strahlentherapie angezeigt. In einer randomisierten Studie hat gegenüber einer konventionellen Fraktionierung eine akzeleriert-hyperfraktionierte Strahlentherapie (CHART; 54 Gy, 3×1,5 Gy pro Tag, Zeitintervall 6 Stunden, Gesamtbehandlungszeit 12 Tage [49]) eine signifikante Verbesserung der 2-Jahres-Überlebensrate (20 vs. 29\%) ergeben und wurde daher als als optimierte Strahlenbehandlung empfohlen [157].

Nach kompletter Tumorresektion eines nicht-kleinzelligen Bronchialkarzinoms kann bei histopathologisch nachgewiesenem mediastinalen Lymphknotenbefall (Stadium III) die postoperative konventionell fraktionierte Strahlentherapie mit 50 Gy empfohlen werden [34]. Im Falle einer R1- bzw. R2-Resektion ist, falls keine Nachresektion durchgeführt wird, die Nachbestrahlung ebenfalls indiziert. Verabreicht wird dann bei einer N0/N1-Situation i.d.R. eine kleinvolumige Bestrahlung von 60-66 Gy. Bei der Kombination von R1- bzw. R2-Resektion und mediastinalen Lymphknotenmetastasen wird i.d.R. eine konventionell fraktionierte Dosis von $50 \mathrm{~Gy}$ auf das Mediastinum, gefolgt von einem Boost von 10-16 Gy auf den residuellen Tumor, dessen Lokalisation intraoperativ mit Metallclips markiert werden sollte, verabreicht. Im Falle einer R1-Situation nach einer Manschettenresektion kann bei geeigneten Fällen mit einem N0-Status in Zentren mit entsprechender Erfahrung auch die endoluminale Brachytherapie eingesetzt werden.

Bei einer präoperativen Strahlentherapie von Pancoast-Tumoren (T3 N0 M0) werden konventionell fraktionierte Dosen zwischen 30 und 50 Gy empfohlen [26].

\section{Strahlentherapie aus palliativer Indikation}

Zur palliativen Bestrahlung des Primärtumor- oder Metastasenbereiches stehen eine Reihe unterschiedlicher Fraktionierungsschemata von Einzeitbestrahlungen mit z.B. $8 \mathrm{~Gy}$, über typisch hypofraktionierte Schemata wie $5 \times 4-5 \mathrm{~Gy}$ oder $10 \times 3 \mathrm{~Gy}$, bis hin zu hochdosierten konventionellen Fraktionierungsschemata (z.B. 20-25 × 2 Gy) zur Verfügung, ohne dass eindeutige Unterschiede in der Effizienz belegt sind $[95,97,98,159,160,163,164]$. Bei kurzer Lebenserwartung und bei alleiniger Berücksichtigung der Symptomreduktion können daher Einzeitbestrahlungen bzw. ultrakurze Behandlungsschemata empfohlen werden. Bei längerer Lebenserwartung können, z. B. unter der Zielstellung einer Remineralisation von Knochenmetastasen, stärker fraktionierte Schemata wie $10 \times 3$ Gy oder $20 \times 2$ Gy eingesetzt werden [162]. Die Bestrahlung von multiplen Hirnmetastasen erfolgt zumeist mit $10 \times 3 \mathrm{~Gy}$. Bei solitären Metastasen sind eine neurochirurgische Intervention oder eine stereotaktische Strahlentherapie zu erwägen [161].

Im Rahmen der Palliativ- oder Rezidivtherapie trägt die Brachytherapie, in Form der Hochdosis-Kurzzeittherapie mit Iridium-192, zusammen mit der Laserung und der Stenteinlage durch temporäre Beseitigung tumorbedingter Stenosierungen zur Verbesserung der Lebensqualität bei. Hierbei sind eine Reihe unterschiedlicher Dosis-Bezugs-Systeme und verschiedene Fraktionierungsschemata etabliert $[99,114,115]$. Bei palliativ intendier- ter Bestrahlung eines okkludierenden Tumorwachstums der zentralen Atemwege kann, im Vergleich zur alleinigen externen Radiotherapie, ein Boost mit endoluminaler Kleinraumbestrahlung zusätzlich zur externen Radiotherapie den palliativen Effekt verbessern [116].

\section{Chemotherapie}

In den Stadien I - III, sowohl des kleinzelligen wie auch des nichtkleinzelligen Bronchialkarzinoms, ist die Chemotherapie bei kurativer Indikation im Rahmen der oben diskutierten interdisziplinärer Therapiekonzepte nicht als alleinige Therapieform indiziert. Bereits bei der Therapieplanung einer sequenziellen oder simultanen Chemoradiotherapie sollte berücksichtigt werden, dass einige Zytostatika (z. B. Mitomycin und, bei simultaner Therapie, Gemcitabin) mit einem höheren Risiko schwerer Strahlennebenwirkungen verbunden sind und daher in dieser Indikation nicht eingesetzt werden sollten. Andere Substanzen (z. B. Cisplatin, Etoposid) sind in dieser Indikation in Studien geprüft und weniger kritisch.

\section{Kleinzelliges Bronchialkarzinom}

Standardisiertes therapeutisches Vorgehen in allen Tumorstadien ist die Durchführung einer Polychemotherapie über 4-6 Zyklen. Etabliert sind Cisplatin bzw. Carboplatin, kombiniert mit Etoposid; Adriamycin bzw. Epirubicin, kombiniert mit Cyclophosphamid und Vincristin; sowie Ifosfamid, kombiniert mit Etoposid. Die initiale Chemotherapiekombination wird bis zum maximalen Ansprechen des Tumors eingesetzt. Sobald in der bildgebenden Diagnostik von einem Chemotherapiezyklus zum nächsten keine weitere Tumorverkleinerung dokumentiert werden kann, sollte umgehend auf ein Alternativprotokoll umgesetzt werden. Dieses sequenzielle Vorgehen ist alternierenden Therapiensequenzen im Stadium IV gleichwertig [165,166] und für Patienten wie Therapeuten besser zu handhaben. Das Alternativprotokoll wird nur dann fortgesetzt, wenn zum jeweils zurückliegenden Kurs ein Ansprechen dokumentiert werden kann. Im idealen Behandlungsablauf wird das Erreichen einer Vollremission nach 4 Therapiezyklen angestrebt. Konsolidierend folgen dann noch 2 weitere Chemotherapiezyklen der gleichen Kombination. Eine weitergehende Erhaltungstherapie nach induzierter Remission hat keinen Stellenwert [167].

Bedeutsam hingegen ist, in den Tumorstadien ohne Fernmetastasen die Chemotherapie zeitgerecht und möglichst ohne Dosisreduktion - zumindest nicht in der Initialphase - durchzuführen [168]. Der mögliche Stellenwert einer Intensivierung der Behandlung in Form der Hochdosischemotherapie mit konsekutiver Retransfusion peripherer Stammzellen ist offen und bedarf der Überprüfung in Studien [169]. Aus der großen Anzahl verfügbarer Chemotherapiekombinationen hat bei Patienten ohne Fernmetastasen eine platinhaltige Kombinationschemotherapie (z.B. Cis- bzw. Carboplatin/Etoposid) den günstigsten therapeutischen Index [170] und ist auch gut mit einer frühen simultanen Radiotherapie zu kombinieren [171].

In der Patientengruppe mit Fernmetastasen sind zwischen den verschiedenen Chemotherapieprotokollen keine bedeutsamen Aktivitätsunterschiede nachweisbar. Für diese Patienten besteht 
nahezu keine Chance auf ein Langzeitüberleben. Daher konzentrieren sich die therapeutischen Ansätze auf eine effektive Palliation unter Erhaltung einer guten Lebensqualität. Empfohlen wird die Durchführung einer intravenösen Polychemotherapie [172]. So wird am besten eine Kontrolle möglicher tumorassoziierter Symptome und damit eine Steigerung der Lebensqualität erreicht. Wahl und Dosierung des Therapieprotokolls sollten nicht schematisch gewählt werden, sondern sich an der Besserung einer klinischen Symptomatik, am Auftreten möglicher Toxizitäten und am Allgemeinzustand des Patienten orientieren. Mit nebenwirkungsarmen Schemata wurden in randomisierten Studien zwar niedrigere Ansprechraten, jedoch der Standardchemotherapie vergleichbare Überlebenszeiten erzielt [173]. Allerdings sollte auch diese Behandlung intravenös und in Form einer Kombinationschemotherapie erfolgen [172].

Im Falle eines Rezidives kann bei Patienten in gutem Allgemeinzustand durch eine weitere Chemotherapie eine erneute Remission - die in der Regel für 3-4 Monate anhält - induziert werden. Einige neue Substanzen wie Paclitaxel, Topotecan und Irinotecan haben das therapeutische Spektrum in der Rezidivsitutation erweitert [175 - 177]. Die Rezidivchemotherapie sollte nur solange fortgesetzt werden, wie ein Ansprechen zu dokumentieren ist. Während Patienten mit „chemosensitiven“ Tumoren (Remissionsdauer nach Abschluss der Primärtherapie $>3$ Monate) auf eine zur Primärbehandlung nicht-kreuzresistente Chemotherapie in einer Größenordnung von 20-30\% ansprechen, sind die Remissionsraten bei Patienten mit „chemorefraktären“ Tumoren (Remissionsdauer nach Abschluss der Primärtherapie < 3 Monate) deutlich ungünstiger [174]. Patienten mit einem Tumorprogress nach länger anhaltender Remission ( $>6$ Monate) können auch mit der erneuten Primärtherapie wieder eine Remission erreichen.

\section{Nicht-kleinzelliges Bronchialkarzinom}

Wirksame Zytostatika beim nicht-kleinzelligen Bronchialkarzinom. Als „wirksam“ bewertet werden solche Zytostatika, die in der Monotherapie beim fernmetastasierten Tumorstadium Remissionsraten $>15 \%$ erzielen. In den 80er Jahren wurde eine solche Monoaktivität für Cisplatin, Ifosfamid, Vindesin und Mitomycin C (Remissionsraten 18-22\%) belegt. Eine ebenfalls noch hinreichende Monoaktivität mit niedrigeren Remissionsraten zeigte sich für Etoposid und Carboplatin [178]. Für weitere Zytostatika konnte in den 90er Jahren ebenfalls eine günstige Monoaktivität gezeigt werden. Hierzu gehören das Pyrimidinanalogon Gemcitabin, die Taxane Paclitaxel und Docetaxel, das hemisynthetische Vinca-Alkaloid Vinorelbin, die bioreduktive Substanz Tirapazamin und der Topoisomerase-I-Hemmer Irinotecan [178].

Mono- vs. Kombinationstherapie. Zwei Metaanalysen belegen signifikante Vorteile einer Kombinationschemotherapie im Vergleich zu einer Monotherapie [179,180]. Neben deutlich günstigeren Remissionsraten (20-35\%) findet sich nach 6 Monaten eine um $10 \%$ höhere Überlebensrate für die Kombinationschemotherapie. Demgegenüber steht eine ausgeprägtere Toxizität der Kombination. So lag die durchschnittliche therapieassoziierte Mortalität in der Monotherapiegruppe $<1 \%$ und in der Kombinationstherapiegruppe bei $2-3 \%[179,180]$. Randomisierte Stu- dien zum Vergleich einer Kombinationstherapie mit einer Monotherapie liegen nur in begrenztem Umfang vor. So wird im Vergleich zu Cisplatin/Etoposid für die Monotherapie mit Gemcitabin in zwei randomisierten Phase-II-Studien eine mediane Überlebenszeit von 30 vs. 26 [181] bzw. von 48 vs. 37 Wochen dokumentiert [182]. Basierend auf den Ergebnissen von Metaanalysen ist die Kombinationsbehandlung die Therapie der Wahl. Auch bei Patienten $>70$ Jahre kann eine nicht-platinhaltige Kombinationsbehandlung (Gemcitabin/Vinorelbin) im Vergleich zur Monotherapie (Vinorelbin) zu einem Überlebensvorteil führen [183]. Liegen aufgrund von Komorbidität oder eines eingeschränkten Allgemeinzustandes (Karnofsky-Index $\leq 60$ ) Kontraindikationen gegen eine zytostatische Kombinationsbehandlung vor, kann eine Monotherapie erwogen werden. In einer randomisierten Studie wurde gezeigt, dass im Vergleich zur alleinigen bestmöglichen supportiven Behandlung eine zusätzliche zytostatische Monotherapie (Vinorelbin) zu einem Überlebensvorteil und zu einer besseren Lebensqualität führt [184].

Therapiedauer. In der Regel sollte nach 2 Therapiezyklen ein Ansprechen auf die zytostatische Behandlung in Form einer Größenabnahme des Tumors bzw. Besserung der Symptome zu verzeichnen sein. Bei fehlendem Ansprechen nach 4 Therapiezyklen ist von einer Fortsetzung dieser Behandlung kein Vorteil für den Patienten zu erwarten [185]. Daher sollte in diesem Fall spätestens dann die Therapie beendet werden. Im randomisierten Vergleich zwischen 3 und 6 Zyklen einer MVP-Therapie (Mitomycin, Vindesine, Cisplatin) fanden sich weder im Hinblick auf Überlebenszeiten noch Symptomenlinderung signifikante Unterschiede [186]. Demgemäß kann empfohlen werden, bei Ansprechen (Symptomenbesserung; Remission) nach 2 Chemotherapiezyklen diese Behandlung zur weiteren Stabilisierung dieses Effektes auf zumindest 4 - nicht aber mehr als 6 - Zyklen auszudehnen. Bei fehlendem Ansprechen sollte nach 2 - spätestens 4 - Therapiezyklen diese Behandlung beendet werden.

Standardtherapie. In Metaanalysen randomisierter Studien wird im Vergleich zur bestmöglichen supportiven Behandlung für die mit einer cisplatinhaltigen Kombinationschemotherapie behandelten Patienten eine signifikante Verlängerung der medianen Überlebenszeit deutlich. Im Vergleich zu nicht-platinhaltigen Kombinationen findet sich dieser Überlebensvorteil nicht [61]. Aufgrund dieser Datenlage wird als „Standardbehandlung“ eine Cisplatin-haltige Kombinationschemotherapie empfohlen. Gut geprüft und im Hinblick auf ihre Effektivität sowie Toxizität validiert sind Kombinationen wie Cisplatin/Etoposid, Cisplatin/ Vinca-Alkaloid oder Mitomycin/Ifosfamid/Cisplatin bzw. Mitomycin/Vinca-Alkaloid/Cisplatin. Im randomisierten Vergleich zwischen diesen platinhaltigen Kombinationen findet sich kein signifikanter Überlebensvorteil für ein bestimmtes Therapieregime. Auch im Vergleich von Cisplatin/Teniposid mit Cisplatin/ Paclitaxel [187] bzw. Cisplatin/Etoposid mit Cisplatin/Gemcitabin [188] finden sich für die jeweils letztgenannten Kombinationen zwar jeweils günstigere Remissionsraten, jedoch keine signifikanten Überlebensvorteile. Lediglich beim Vergleich von Cisplatin/Vinorelbin mit Cisplatin/Vindesin zeigte sich neben einer günstigeren Remissionsrate auch eine signifikante Verlängerung der medianen Überlebenszeit (40 vs. 32 Wochen) für die erstgenannte Kombination [189]. 
Im randomisierten Vergleich von Cisplatin $\left(120 \mathrm{mg} / \mathrm{m}^{2}\right)$ vs. Carboplatin $\left(325 \mathrm{mg} / \mathrm{m}^{2}\right)$, jeweils in der Kombination mit Etoposid, zeigte sich für Cisplatin eine günstigere Remissionsrate ( $27 \%$ vs. $16 \%$ ) bei allerdings auch ausgeprägterem Toxizitätsprofil (Myelosuppression; Nephrotoxizität). Die medianen Überlebenszeiten (30 vs. 27 Wochen) unterschieden sich nicht signifikant [190]. Im Verhältnis zu Cisplatin wurde das Carboplatin, gemäß der heute üblichen Dosierung nach AUC, relativ niedrig dosiert. Ein Vergleich in äquitoxischer Dosierung beider Platinderivate steht aus. Die vorgenannte Studie belegt - bei unterschiedlichem Toxizitätsspektrum - die Effektivität beider Zytostatika in der Kombinationsbehandlung, wobei für Cisplatin-basierte Kombinationen die Datenlage insgesamt valider ist.

Für Patienten mit Fernmetastasen und (a) hinreichendem Allgemeinzustand (Karnofsky-Index $\geq 70$ ) sowie (b) fehlender eine solche Behandlung ausschließenden Komorbidität, werden zwei Zyklen einer platinhaltigen Polychemotherapie empfohlen. Im Falle eines Ansprechens (Symptomenreduktion; Tumorverkleinerung über 50\%) sollte die Chemotherapie auf vier bis sechs Behandlungszyklen ausgedehnt werden. Die Evidenz zur Behandlung von Patienten mit einem Karnofsky-Index $\leq 60$ mit einer platinhaltigen Polychemotherapie ist eingeschränkt, da in den entsprechenden Studien allenfalls 10-20\% der eingeschlossenen Patienten diesen Allgemeinzustand (ECOG 2) hatten.

Bei Patienten (a) in eingeschränktem Allgemeinzustand (Karnofsky-Index $\leq 60$; jedoch so hinreichend, dass zusätzlich zum Nachtschlaf kein weiterer Ruhebedarf von mehr als 6 Stunden pro Tag besteht) oder (b) mit einer eine platinhaltige Chemotherapie ausschließenden Komorbidität kann eine zytostatische Monotherapie (z. B. Vinorelbin; z. B. Gemcitabin) erwogen werden. Diese Behandlung sollte nur fortgeführt werden, solange sie (a) gut verträglich ist und (b) ein Ansprechen der Erkrankung (Symptomenreduktion) dokumentiert werden kann.

Zweitlinientherapie. Bei Patienten mit Fernmetastasen und erneuter Erkrankungsprogression nach platinhaltiger Vorbehandlung können mit einer zytostatischen Mono- oder Kombinationstherapie Remissionsraten in der Größenordnung von 20\% erreicht werden [191,192]. In einer randomisierten Studie wurde gezeigt, dass nach platinhaltiger Vorbehandlung für diese Patienten im Vergleich zur alleinigen bestmöglichen supportiven Behandlung der zusätzliche Einsatz des Zytostatikums Docetaxel in der Zweitlinientherapie einen gewissen Überlebensvorteil erbringt (mediane Überlebenszeit 4,6 vs. 7,5 Monate) [193]. Für ausgewählte Patienten in gutem Allgemeinzustand (KarnofskyIndex 270 ) kann eine Zweitlinientherapie empfohlen werden. Diese sollte möglichst in randomisierten Studien erfolgen.

\section{Endoskopische Therapieverfahren}

Die Domäne der therapeutischen Bronchoskopie sind palliative Therapiemaßnahmen (vgl. Abschnitt Palliative Therapiemaßnahmen). Bei funktionell inoperablen oder nur mit höchstem Risiko operablen Patienten mit kleinen, in den zentralen Atemwegen lokalisierten Tumoren können diese Verfahren auch erfolgreich in der Primärtherapie eingesetzt werden [194].
Es ist damit zu rechnen, dass durch neue Screeningtechniken mehr Frühkarzinome und In-situ-Karzinome aufgedeckt werden. In einer Verlaufsstudie mit Autofluoreszenz-Bronchoskopie entwickelten 56\% der Patienten aus einem Carcinoma in situ ein invasives Karzinom und bei $44 \%$ der Patienten mit einem Carcinoma in situ wurde an mindestens einer weiteren Stelle im Bronchialsystem ein Neoplasma gefunden [195]. Ob ein Carcinoma in situ operativ, lokal oder überhaupt nicht behandelt werden sollte, wird noch kontrovers diskutiert [196]. In einem Kollektiv von 98 Patienten mit Carcinoma in situ oder radiologisch negativem Frühkarzinom lag die 5-Jahres-Überlebensrate nach Resektion bei $81 \%$. In dem Beobachtungszeitraum der Studie wurde bei 13 Patienten ein zweiter Tumor aufgedeckt [197]. Das Risiko, nach kurativer Operation eines Bronchialkarzinoms im Stadium I einen Zweittumor zu entwickeln, liegt für Patienten mit nichtkleinzelligem Karzinom bei $2 \%$ pro Patient/Jahr und bei Patienten mit kleinzelligem Karzinom bei $10 \%$ pro Jahr [198]. Erneute operative Maßnahmen sind bei derartigen Tumorrezidiven bzw. dem Aufdecken von metachron entstandenen Karzinomen selten möglich. Aus diesen Gründen wird hier die lokale Behandlung von Frühtumoren als mögliche Alternative diskutiert [199]. Der Erhalt des Parenchyms muss dabei gegen eine möglicherweise schlechtere Prognose abgewogen werden.

Bei funktionell inoperablen Tumoren, die die Bronchuswand nicht überschritten haben, kommen die gleichen endoskopischen Verfahren in Betracht, mit denen in palliativer Absicht die Tumormasse verringert werden kann (Abb.1). So werden in dieser Situation mit einer endoluminalen Kleinraumbestrahlung (Hochdosis-Brachytherapie bis $35 \mathrm{~Gy}$ ) histologisch gesicherte, komplette lokale Tumorkontrollraten von $83 \%$ erreicht [200]. Ein Jahr nach Brachytherapie lebten noch 78\% der Patienten, nach zwei Jahren noch 58\%. Auch mit Elektrokauter [201] und Kryotherapie [202] lassen sich solch minimale Tumorausdehnungen in über $80 \%$ der Fälle beseitigen. Bei multilokulären kleineren $(<1 \mathrm{~cm}$ im Durchmesser) oder flach spreitenden Tumoren, die jeweils nur eine endobronchiale Manifestation zeigen, kann durch die photodynamische Therapie (PDT) mit Photofrin in bis zu $80 \%$ der Fälle eine Tumoreradikation erreicht werden $[203,204]$. In dem Mayo-Clinic-Protokoll für frühe Plattenepithelkarzinome waren mit Einsatz der PDT nach einer mittleren Nachbeobachtungszeit von 68 Monaten 43\% der Patienten tumorfrei [205].

\section{Nachsorge des Bronchialkarzioms}

Die Nachsorge eines an einem Bronchialkarzinom erkrankten Patienten dient zum einen der möglichst frühzeitigen Erfassung und Behandlung von therapiebedingten Nebenwirkungen und zum anderen der Kontrolle der Tumorkrankheit. Bei kurativ behandelten Patienten zielt die Nachsorge auf die möglichst frühzeitige Diagnose von Lokalrezidiv oder Zweittumoren, um so durch die Option eines weiteren kurativen chirurgischen Eingriffes die Heilungschance zu erhalten. Bei Patienten mit Fernmetastasen oder nicht-kurativer Behandlung stehen Symptomenkontrolle und der Erhalt der bestmöglichen Lebensqualität im Vordergrund. 
Bereits im Stadium II eines nicht-kleinzelligen Bronchialkarzinoms (NSCLC) ist nach primär kurativer Resektion im Verlauf von 5 Jahren in 50\% der Fälle mit Rezidiven zu rechnen [206]. Das Rezidivmuster in den frühen Stadien (I/II) des NSCLC verteilt sich wie folgt: Lokalrezidive $10-20 \%$; Fernmetastasen $20-30 \%$; Zweittumoren 2-15\% [207-209].

Nach Abschluss eines kurativen Therapiekonzeptes zielt die Nachsorge auf a) die möglichst frühzeitige Diagnose eines Lokalrezidives oder von Zweittumoren sowie b) das möglichst frühzeitige Erfassen von Nebenwirkungen und Komplikationen der Therapie. Daher werden hier in den ersten beiden Jahren nach Abschluss der Behandlung Nachsorgeuntersuchungen im Abstand von 3 Monaten empfohlen und dann alle 6 Monate bis zum 5. Jahr nach Abschluss der Behandlung. Diese Empfehlung basiert auf der Erfahrung der Autoren und publizierten Empfehlungen anderer Institutionen. Durch prospektive Studien validierte Empfehlungen zu Frequenz und Umfang von Nachsorgeuntersuchungen existieren derzeit nicht.

Als kurativ angesehen werden können Behandlungskonzepte, die in den Stadien I-III des nicht-kleinzelligen wie kleinzelligen Bronchialkarzinoms mit einer kompletten Tumorresektion abgeschlossen wurden bzw. bei denen nach Chemo- und Strahlentherapie eine Vollremission erreicht wurde. Darüber hinaus besteht auch mit Erreichen einer parziellen Remission bzw. fehlenden Tumorprogression nach Chemo- und Strahlentherapie sowie nach einer R1-/R2-Resektion - wenn eine adäquate Strahlentherapie zur lokalen Tumorkontrolle erfolgt ist - noch eine kurative Chance.

Demgegenüber ist das Therapiekonzept bei Patienten mit Fernmetastasen oder einer nicht zu kontrollierenden lokalen Progression palliativ. Hier zielt die Nachsorge auf a) eine möglichst gute Symptomenkontrolle und gute Lebensqualität sowie b) das Erfassen von Nebenwirkungen oder Komplikationen der Therapie. Die Nachsorgeintervalle sollten sich an der klinischen Symptomatik orientieren und können zunächst 3 Monate betragen.

Von zentraler Bedeutung bei jedem Nachsorgetermin sind die Anamneseerhebung (Allgemeinbefinden, Gewichtsverlauf, Schluckbeschwerden, Hustencharakteristik und -intensität, Auswurf, Hämoptysen, Atemnot, Schmerzen) und klinische Untersuchung (Herz und Lunge, das Erfassen einer oberen Einflussstauung bzw. von Lymphknotenvergrößerungen, Leber und Skelett als mögliche Orte einer Metastasierung). Darüber hinaus wird jeweils eine Röntgenaufnahme der Thoraxorgane in zwei Ebenen empfohlen. Der weitere Untersuchungsumfang erfolgt symptomenorientiert bzw. aufgrund anamnestischer Hinweise.

In den letzten Jahren wurde neben der Spiral-CT die Positronenemissionstomographie und die Fluoreszenzbronchoskopie für den klinischen Einsatz verfügbar. Darüber hinaus bietet die molekularbiologische Analyse des Tumorgewebes nach kurativer Behandlung die Möglichkeit zur Charakterisierung von Patientengruppen mit hohem Rezidivrisiko [2]. Der Stellenwert dieser Verfahren für die Nachsorge von Patienten mit Bronchialkarzinomen bedarf der weiteren Evaluation in klinischen Studien.
1 Mountain C. Revisions in the international system for staging lung cancer. Chest 1997; 111: 1710-1717

2 Thomas M, Gatzemeier U, Goerg R, Matthiessen W, Morr H, Schönfeld N, Ukena D, Stamatis G. Empfehlungen zur Diagnostik des Bronchialkarzinoms. Pneumologie 2000; 54: 361 - 371

3 Pignon JP, Arriagada R, Ihde DC, Johnson DH, Perry MC, Souhami RL, Brodin O, Joss RA, Kies MS, Lebeau B et al. A metaanalysis of thoracic radiotherapy for small cell lung cancer. N Engl J Med 1992; 327: $1618-1624$

4 Warde P, Payne D. Does thoracic irradiation improve survival and local control in limited-stage small-cell carcinoma of the lung? A metaanalysis. J Clin Oncol 1992; 10: 890-895

5 Murray N, Coy P, Pater JL, Hodson I, Arnold A, Zee BC, Payne D, Kostashuk E, Evans W, Dixon P, Sadura A, Feld R, Levitt M, Wierzbicki R, Ayoub J, Maroun J, Wilson K. Importance of timing for thoracic irradiation in the combined modality treatment of limited-stage smallcell lung cancer. J Clin Oncol 1993; 11: 336-344

6 Jeremic B, Shibamoto Y, Acimovic L, Milisavlejevic S. Initial versus delayed accelerated hyperfractionated radiation therapy and concurrent chemotherapy in limited small-cell lung cancer. A randomized study. J Clin Oncol 1997; 15: 893 - 899

7 Goto K, Nishiwaki Y, Takada M, Fukuoka M, Kawahara M, Sugiara T, Kurita Y, Watanabe K, Noda K, Yoshimura K, Tamura T, Saijo N. Final results of a phase-III-study of concurrent versus sequential thoracic radiotherapy (TRT) in combination with cisplatin (P) and etoposide (E) for limited-stage small cell lung cancer (LD-SCLC). The Japan Clinical Oncology Group (JCOG) Study. Proc Am Soc Clin Oncol 1999; 18: 468a (abs. 1805)

8 Work E, Nielsen O, Bentzen S, Fode K, Palshof T. Randomized study of initial versus late chest irradiation combined with chemotherapy in limited-stage small-cell lung cancer. J Clin Oncol 1997; 15: 3030-3037

9 Perry M, Eaton W, Propert K, Ware J, Zimmer B, Chahinian P, Skarin A, Carey R, Kreisman H, Faulkner C, Comis R, Green M. Chemotherapy with or without radiation therapy in limited small-cell lung cancer. N Engl J Med 1987; 316: 912 -918

${ }^{10}$ Perry M, Herndon J, Eaton W, Green M. Thoracic radiation therapy added to chemotherapy in limited small cell lung cancer: an update of cancer and leukemia group B (CALGB) study 8083. Proc Am Soc Clin Oncol 1996; 15: 384 (abs. 1150)

${ }^{11}$ Turrisi A, Kim K, Blum R, Sause WT, Livingston RB, Komaki K, Wagner $\mathrm{H}$, Aisner S, Johnson D. Twice-daily compared with once-daily thoracic radiotherapy in limited small-cell lung cancer treated concurrently with cisplatin and etoposide. N Engl J Med 1999; 340: 265-271

12 Auperin A, Arriagada R, Pignon JP, Le Pechooux C, Gregor A, Stephens RJ, Kristjansen PEG. Prophylactic cranial irridiation for patients with small-cell lung cancer in complete remission. N Engl J Med 1999; 341: $476-484$

${ }^{13}$ Shepherd FA, Ginsberg RJ, Patterson GA, Evans WK, Feld R. A prospective study of adjuvant surgical resection after chemotherapy for limited small-cell lung cancer. A University of Toronto Lung Oncology Group Study. J Thorac Cardiovasc Surg 1989; 97: 177-186

${ }^{14}$ Davis S, Crino L, Tonato M, Darwish S, Pelicci PG. A prospective analysis of chemotherapy following surgical resection of clinical stage I-II small-cell lung cancer. Am J Clin Oncol 1993; 16: 93 - 95

15 Karrer K, Shields TW, Denck H, Hrabar B, Vogt-Moykopf I, Salzer GM. The importance of surgical and multimodality treatment for smallcell bronchial carcinoma. J Thorac Cardiovasc Surg 1989; 97: $168-176$

${ }^{16}$ Kaiser D, Fritzsche A, Matthiessen W. Operationsindikation beim kleinzelligen Bronchialkarzinom. Dtsch Med Wochenschr 1992; 117: $103-106$

${ }^{17}$ Jeremic B, Shibamoto Y, Nicolic N, Milicic B, Milisavljevic S, Dagovic A, Aleksandrovic J, Radosavljevid-Asic G. Role of radiation therapy in the combined-modality treatment of patients with extensive disease small-cell lung cancer: a randomized study. Journal of Clinical Oncology 1999; 17: 2092 - 2099

18 Pearson FG, De Larue NC, Ilves R, Todd TR, Cooper JD. Significance of positive superior mediastinal nodes identified at mediastinoscopy in patients with resectable cancer of the lung. J Thorac Cardiovasc Surg 1982; 83: $1-11$ 
${ }^{19}$ Pitz CC, Brutel-de IR, Elbers HR, Westermann CJ, van den Bosch J. Surgical treatment of 125 patients with non-small cell lung cancer and chest wall involvement. Thorax 1996; 51: 846 - 850

${ }^{20}$ Gould PM, Bonner JA, Sawyer TE, Deschamps C, Lange CM, Li H. Patterns of failure and overall survival in patients with completely resected T3 N0 M0 non-small cell lung cancer. Int J Radiat Oncol Biol Phys 1999; 45: 91 - 95

${ }^{21}$ Paulson DL. The role of preoperative radiation therapy in the surgical management of cacinoma in the superior pulmonary sulcus. Front Radiat Ther Oncol 1970; 5: 177-187

${ }^{22}$ Ahmad K, Fayos JV, Kirsh MM. Apical lung carcinoma. Cancer 1984; 54: $913-917$

${ }^{23}$ Attar S, Krasna MJ, Sonett JR, Hankins JR, Slawson RG, Suter CM, McLaughlin JS. Superior sulcus (Pancoast) tumor: experience with 105 patients [see comments]. Ann Thorac Surg 1998; 66: 193-198

${ }^{24}$ Paulson DL. Carcinomas in the superior pulmonary sulcus. J Thorac Cardiovasc Surg 1975; 70: 1095-1104

${ }^{25}$ Maggi G, Casadio C, Pischedda F, Giobbe R, Cianci R, Ruffini E, Molinatti M, Mancuso M. Combined radiosurgical treatment of Pancoast tumor. Ann Thorac Surg 1994; 57: 198-202

${ }^{26}$ Stuschke M, Heilmann HP. Lunge und Mediastinum. In: Scherer E, Sack H (Hrsg). Strahlentherapie, 4. Aufl. Berlin: Springer, 1996: $683-718$

${ }^{27}$ Arcasoy SM, Jett JR. Superior pulmonary sulcus tumors and pancoast syndrome. N Engl J Med 1997; 337: 1370-1376

${ }^{28}$ Ichinose Y, Hara N, Ohta M, Yano T, Maeda K, Asoh H, Katsuda Y. Is T factor of the TNM staging system a predominat prognostic factor in pathologic stage I non-small cell lung cancer? J Thorac Cardiovasc Surg 1993; 106: $90-94$

${ }^{29}$ Mountain C. New prognostic factors in lung cancer. Chest 1995; 108: $246-254$

${ }^{30}$ Cote RJ, Beattie EJ, Chaiwun B, Shi SR, Harvey J, Chen SC, Sherrod AE, Groshen S, Taylor CR. Detection of occult bone marrow micrometastases in patients with operable lung carcinoma. Ann Surg 1995; 222: $415-425$

${ }^{31}$ Passlick B, Kubuschok B, Izbicki JR, Thetter O, Pantel K. Isolated tumor cells in bone marrow predict reduced survival in node-negative nonsmall cell lung cancer. Ann Thorac Surg 1999; 68: 2053-2058

32 Thomas M, Macha HN, Rübe C, van de Loo J. Stellenwert der Chemotherapie in der Behandlung des nicht-kleinzelligen Bronchialkarzinoms. Dtsch med Wschr 1995; 120: 1627-1630

33 PORT. Meta-analysis Trialists Group. Postoperative radiotherapy in non-small-cell lung cancer: Systematic review and meta-analysis of individual patient data from 9 randomized controlled trials. Lancet 1998; 352: $257-263$

${ }^{34}$ Klages HT, Stuschke M. Postoperative Radiotherapie beim kurativ resezierten nicht-kleinzelligen Bronchialkarzinom. Strahlenther Onkol 1999; 175: $134-138$

${ }^{35}$ Rosell R, Gomez-Codina J, Camps C, Ryan MB, Putnam JB, Lee LS, Dhingra H, De Caro L, Chasen M, McGavran M, Atkinson EN, KiHong W. A randomized trial comparing preoperative chemotherapy plus surgery with surgery alone in patients with non-small-cell lung cancer. N Engl J Med 1994; 330: 153 - 158

${ }^{36}$ Roth J, Fossela F, Komaki R, Ryan MB, Putnam JB, Lee LS, Dhingra H, De Caro L, Chasen M, McGavran M, Atkinson EN, KiHong W. A randomized trial comparing perioperative chemotherapy and surgery with surgery alone in resectable stage IIIA non-small-cell lung cancer. J Natl Cancer Inst 1994; 86: 673-680

${ }^{37}$ Albain KS, Rusch VW, Crowley JJ, Rice TW, Turrisi AT, Weick JK, Lonchyna VA, Presant CA, McKenna RJ, Gandara DR, Fosmire H, Taylor SA, Stelzer KJ, Beasley KR, Livingston RB. Concurrent cisplatin/etoposide plus chest radiotherapy followed by surgery for stages IIIA (N2) and IIIB non-small cell lung cancer: mature results of Southwest Oncology Group phase II study 8805. J Clin Oncol 1995; 13: 1880-1892

38 Eberhardt W, Wilke H, Stamatis G, Stuschke M, Harstrick A, Menker H, Krause B, Müller MR, Stahl M, Flasshove M, Budach V, Greschuchna D, Konietzko N, Sack H, Seeber S. Preoperative chemotherapy followed by concurrent chemoradiation therapy based on hyperfractionated accelerated radiotherapy and definitive surgery in locally advanced non-small-cell lung cancer: mature results of a phase II trial. J Clin Oncol 1998; 16: 622-634

${ }^{39}$ Thomas M, Rübe C, Semik M, von Eiff M, Freitag L, Macha HN, Wagner W, Klinke F, Sheld HH, Willich N, Berdel WE, Junker H. Chemotherapy and subsequent twice-daily chemoradiation before surgery in stage III non-small cell lung cancer: impact of tumor regression on survival. J Clin Oncol 1999 (a); 17: 1185-1193
${ }^{40}$ Thomas M, Rübe C, Semik M, Steppling H, Macha H, Deimling A, Klinke F, Deppermann K, Clemens M, Dornoff W, Weber W, Berdel W. Randomized trial of chemotherapy and twice-daily chemoradiation versus chemotherapy alone before surgery in stage III non-small cell lung cancer: interim of toxicity. Proc am Soc Clin Oncol 1999 (b); 18: 458a (abs. 1769)

${ }^{41}$ Dillman RO, Seagren SL, Propert KJ, Guerra J, Eaton WL, Perry MC, Carey RW, Frei EF, Green MR. A randomized trial of induction chemotherapy plus high-dose radiation versus radiation alone in stage III non-small-cell lung cancer. N Engl J Med 1990; 323: 940-945

${ }^{42}$ Le Chevalier T, Arriagda R, Quoix E, Ruffie P, Martin M, Tarayre M, Lacombe Terrier MJ, Douillard JY, Laplanche A. Radiotherapy alone versus combined chemotherapy and radiotherapy in nonresectable nonsmall cell lung cancer: First analysis of a randomized trial in 353 patients. J Natl Cancer Inst 1991; 83: 417-423

${ }^{43}$ Le Chevalier T, Arriagda R, Tarayre M, Lacombe Terrier MJ, Laplanche A, Quoix E, Ruffie P, Martin M, Douillard JY. Significant effect of adjuvant chemotherapy on survival in locally advanced non-small cell lung carcinoma (letter). J Natl Cancer Inst 1992; 84: 58

${ }^{44}$ Sause WT, Scott C, Taylor S, Johnson D, Livingstone R, Komaki R, Emami B, Curran WJ, Byhardt RW, Turrisi AT, Dar AR, Cox JD. Radiation Therapy Oncology Group (RTOG) 80-08 and Eastern Cooperative Oncology Group (ECOG) 4588: preliminary results of a phase III trial in regionally advanced, unresectable non-small cell lung cancer. J Natl Cancer Inst 1995; 87: 198 - 205

${ }^{45}$ Sause W, Kolesar P, Taylor S, Johnson D, Livingston R, Komaki R, Emami B, Curran W, Byhardt R, Dar A, Turrisi A. Final results of phase III trial in regionally advanced non-small cell lung cancer. RTOG, ECOG and SWOG. Chest 2000; 117: $358-364$

${ }^{46}$ Dillman RO, Herndon J, Seagren SL, Eaton WL, Green MR. Improved survival in stage III non-small cell lung cancer: seven year follow up of CALGB 8433 trial. J Natl Cancer Inst 1996; 88: 1210-1215

${ }^{47}$ American Society of Clinical Oncology. Clinical practice guidelines for the treatment of unresectable non-small-cell lung cancer. J Clin Oncol 1997; 15: 2996-3018

${ }^{48}$ Choi N, Baumann M, Flentje M, Kellokumpu-Lehtinen P, Senan S, Zamboglou N, Kosmidis P. Predictive factors of radiation response in non-small cell lung cancer: present status. Lung Cancer 2001; 31: $43-56$

${ }^{49}$ Saunders M, Dische S, Barrett A, Harvey A, Gibson D, Parmar M. Continuous hyperfractionated accelerated radiotherapy (CHART) versus conventional radiotherapy in non-small cell lung cancer: a randomised multicenter trial. Lancet 1997; 350: 161 - 165

${ }^{50}$ Schaake-Konig C, van den Bogaert W, Dalesio O, Festen J, Hoogenhout H, van Houtte P, Kirkpatrick A, Koolen M, Maat B, Nijs A, Renaud A, Rodrigus P, Schuster-Uitterhoeve L, Sculier JP, van Zandwijk N, Bartelink $\mathrm{H}$. Effects of concomittand cisplatin and radiotherapy on inoperable non-small-cell lung cancer. N Engl J Med 1992; 326: 524-530

51 Jeremic B, Shibamoto L, Acimovic L, Djuric L. Randomized trial of hyperfractionated radiation therapy with or without concurrent chemotherapy for stage III non-small cell lung cancer. J Clin Oncol 1995; 13: $452-458$

52 Jeremic B, Shibamoto L, Acimovic L, Milisavljevic S. Hyperfractionated radiation therapy with or without concurrent low dose daily carboplatin/etoposide for stage III non-small-cell lung cancer: a randomized study. J Clin Oncol 1996; 14: 1065 - 1070

${ }^{53}$ Furuse K, Fukuoka M, Kawahara M, Nishikawa H, Takada Y, Kudoh S, Katagami N, Ariyoshi Y. Phase III study of concurrent versus sequential thoracic radiotherapy in combination with Mitomycin, Vindesine, and Cisplatin in unresectable stage III non-small lung cancer. J Clin Oncol 1999; 17: $2692-2699$

${ }^{54}$ Curran W, Scott C, Langer C, Komaki R, Lee J, Hauser S, Movsas B, Wassermann T, Rosenthal S, Byhardt R, Sause W, Cox J. Phase III comparison of sequential vs concurrent chemoradiation for pts with unresected stage III non-small cell lung cancer: Initial report of Radiation Therapy Oncology Group (RTOG) 9410. Proc Am Soc Clin Oncol 2000; 19: 484a (abs. 1891)

55 Saunders M, Dische S, Barrett A, Harvey A, Griffiths G, Parmar M (on behalf of the CHART steering committee). Continuous hyperfractionated accelerated radiotherapy (CHART) versus conventional radiotherapy in non-small-cell lung cancer: mature data from the randomised multicentre trial. Radiother Oncol 1999; 52: 137-148

${ }^{56}$ Baumann M. Accelerated radiation therapy in non-small cell lung cancer. Radiother Oncol 1999; 52: 97 -99 
${ }^{57}$ Baumann M, Appold S, Zips D, Nestele U, Petersen C, Herrmann Th. Modified fractionation in the radical treatment of non-small cell lung cancer. Front Radiat Ther Oncol 2000; 34: 80-88

${ }^{58}$ Baumann M, Herrmann T, Matthiessen W, Koch R, Strelocke K, Paul U für das CHARTWEL-Bronchus Protokollkomitee (1997) CHARTWELBronchus (ARO 97-1). Eine randomisiert-multizentrische Studie zum Vergleich einer konventionell fraktionierten Strahlentherapie mit CHARTWEL-Bestrahlung bei inoperablen nicht-kleinzelligen Bronchialkarzinomen. Strahlenther Onkol 1997; 173: 663-667

${ }^{59}$ Thomas M. Tumorassoziierte Prognoseparameter beim nicht-kleinzelligen Bronchialkarzinom. Pneumologie 1997; 51: 669-677

${ }^{60}$ Thomas M, Rübe C, Semik M, von Eiff M, Klinke F, Macha HN, Freitag L, Scheld HH, Willich N, Berdel WE, Junker K. Trimodality therapy in stage III non-small cell lung cancer: prediction of recurrence by pretherapeutic assessment of p185neu. Eur Respir J 1999(c); 13: 424-429

${ }^{61}$ Non-small cell lung cancer collaborative group. Chemotherapy in non-small cell lung cancer: a meta-analysis using updated data on individual patients from 52 randomized clinical trials. BMJ 1995; 311: 899-909

62 Le Chevalier T. Chemotherapy for advanced non-small cell lung cancer. Chest 1996; 109: 107s-109s

${ }^{63}$ Ellis PA, Smith I, Hardy J, Nicolson M, Talbot D, Ashley S, Priest K. Symptom relief with MVP (mitomycin C, vinblastin and cisplatin) chemotherapy in advanced non-small cell lung cancer. Br J Cancer 1995; 71: 366-370

${ }^{64}$ Thatcher N, Niven RM, Anderson H. Agressive versus nonaggressive therapy for metastatic non-small cell lung cancer. Chest 1996; 109: $87 s-92 s$

${ }^{65}$ Wirbel RJ, Mutschler WE. Die chirurgische Therapie von Knochenmetastasen. Zentralbl Chir 1995; 120: 707-715

${ }^{66}$ Janjan NA. Radiation for bone metastases: conventional techniques and the role of systemic radiopharmaceuticals. Cancer 1997; 80: $1628-1645$

${ }^{67}$ Sullivan FJ. Palliative radiotherapy for lung cancer. In: Pass HI, Mitchell JB, Johnson DH, Turrisi AT (ed). Lung Cancer. Principles and Practice. Philadelphia-New York: Lippincott-Raven, 1996: 775 - 789

${ }^{68}$ Berenson JR, Lichtenstein A, Porter L, Dimopoulos MA, Bordoni R, George S, Lipton A, Keller A, Ballester O, Kovacs M, Blacklock H, Bell R, Simeone J, Reitsma D, Heffernan M, Seaman J, Knight R. Efficacy of pamidronate in reducing skeletal events in patients with advanced multiple myeloma. N Engl J Med 1996; 334: 488-493

${ }^{69}$ Hortobagyi GN, Theriault RL, Porter L, Blayney D, Lipton A, Sinoff C, Wheeler H, Simeone JF, Seaman J, Knight RD. Efficacy of pamidronate in reducing skeletal compliancations in patients with breast cancer and lytic bone metastases. N Engl J Med 1996; 335: 1785-1791

70 Theriault RL, Lipton A, Hortoagyi GN, Leff R, Glück S, Stewart JF, Costello S, Kennedy I, Simeone J, Seaman JJ, Knight RD, Mellars K, Heffernan M, Reitsma DJ. Pamidronate reduces skeletal morbidity in women with advanced breast cancer and lytic bone lesions: A randomized, placebo-controlled trial. J Clin Oncol 1999; 17: 846-854

${ }^{71}$ Ryan GF, Ball DL, Smith JG. Treatment of brain metastases from primary lung cancer. Int J Radiat Oncol Biol Phys 1995; 31: 273-278

72 Patchell RA, Tibbs PA, Walsh JW, Dempsey RJ, Maruyama Y, Kryscio RJ, Markesbery WR, Macdonald JS, Young B. A randomized trial of surgery in the treatment of single metastases to the brain. N Engl J Med 1990; 322: 494-500

${ }^{73}$ Sause WT, Crowley JJ, Morantz R, Rotman M, Mowry PA, Bouzaglou A, Borst JR, Selin H. Solitary brain metastasis: results of an RTOG/SWOG protocol evaluation surgery + RT versus RT alone. Am J Clin Oncol 1990; $13: 427-432$

${ }^{74}$ Cho KH, Hall WA, Gerbi BJ, Higgins PD, Bohen M, Clark HB. Patient selection criteria for the treatment of brain metastases with sterotactic radiosurgery. J Neurooncol 1998; 40: 73-86

${ }^{75}$ Flickinger JC, Lunsford LD, Somaza S, Konziolka D. Radiosurgery: its role in brain metastasis management. Neurosurg Clin N Am 1996; 7: 497-504

${ }^{76}$ Dempke W, Behrmann C, Schöber C, Büchele T, Grothey A, Schmoll $\mathrm{H}-\mathrm{J}$. Diagnostisches und therapeuptisches Management der oberen Einflussstauung. Med Klinik 1999; 94: 681-684

${ }^{77}$ Markman M. Diagnosis and management of superior vena cava syndrome. Cleve Clin J Med 1999; 66: 59-61

78 Ostler PJ, Clarke DP, Watkinson AF, Gaze MN. Superior vena cava obstruction: a modern management strategy. Clin Oncol R Coll Radiol 1997; 9: $83-89$
${ }^{79}$ Hochrein J, Bashore TM, O'Laughin MP, Harrison K. Percutaneous stenting of superior vena cava syndrome: a case report and review of theliterature Am J Med 1998; 104: 78 - 84

${ }^{80}$ Nesbitt JC. Surgical management of superior vena cava syndrome. In: Pass HJ, Mitchell JB, Johnson DH, Turrisi AT (eds). Lung Cancer. Principles and Practice Philadelphia-New York: Lippincott-Raven, 1996: $671-681$

${ }^{81}$ Byrne TN. Spinal cord compression from epidural metastases. N Engl J Med 1992; 327: 614-619

82 Soerensen S, Helweg-Larsen S, Mouridsen H, Hansen HH. Effect of high-dose dexamethasone in carcinomateous metastatic spinal cord compression treated with radiotherapy: a randomised trial. Eur J Cancer 1994; 30A: 22-27

${ }^{83}$ Bach F, Agerlin N, Sorensen JB, Rasmussen TB, Dombernowsky P, Sorensen PS, Hansen $\mathrm{HH}$. Metastatic spinal cord compression secondary to lung cancer. J Clin Oncol 1992; 10: 1781 - 1787

${ }^{84}$ Loblaw DA, Laperriere NJ. Emergency treatment of malignant extradural spinal cord compression: an evidence-based guideline. J Clin Oncol 1998; 16: 1613-1624

85 Maranzano E, Latini P. Effectiveness of radiation therapy without surgery in metastatic spinal cord compression: final results from a prospective trial. Int J Radiat Oncol Biol Phys 1995; 32: 959-967

${ }^{86}$ Solberg A, Bremnes RM. Metastatic spinal cord compression: diagnostic delay, treatment, and outcome. Anticancer Res 1999; 19: 677-684

${ }^{87}$ Loddenkemper R. Thoracoscopy - state of the art. Eur Respir J 1998; 11: $213-221$

88 Rodriguez-Panadero F, Antony VB. Pleurodesis: state of the art. Eur Respir J 1997; 10: 1648 - 1654

${ }^{89}$ Hentrich M, Hartenstein R. Behandlung maligner Körperhöhlenergüsse. Internist 1997; 38: 794-804

${ }^{90}$ Waller DA, Morritt GN, Forty J. Video-assisted thoracoscopic pleurectomy in the management of malignant pleural effusion. Chest 1995; 107: $1454-1456$

${ }^{91}$ Berg M, Heisel A, Ukena D, Schäfers H-J, Schieffer H. Behandlung des malignen Perikardergusses. Med Klinik 1997; 92: 27 - 30

92 Cherny NI, Portenoy RK. The management of cancer pain. CA Cancer J Clin 1994; 44: $263-303$

${ }^{93}$ World Health Organization [WHO]. Cancer pain relief. With a guide to opioid availability. Cancer Pain Relief 1996; 1-63

${ }^{94}$ Zech DF, Grond S, Lynch J, Hertel D, Lehmann KA. Validation of World Health Organization guidelines for cancer pain relief. A 10-year prospective study. Pain 1995; 63: 65-76

95 Bone Pain Trial Working Party. 8 Gy single fraction radiotherapy for the treatment of metastatic skeletal pain: randomized comparison with a multifraction schedule over 12 months of patient follow-up. Radiother Oncol 1999; 52: 111 - 121

${ }^{96}$ Reichle G, Freitag L, Kullmann HJ, Prenzel R, Macha HN, Farin G. Argon plasma coagulation in bronchology: a new method - alternative or complementary. J Bronchol 2000; 7: 109-117

${ }^{97}$ Medical Research Concil Lung Cancer Working Party. A Medical Research Council (MRC) randomized trial of palliative radiotherapy with two fractions or a single fraction in patients with inoperable non-small-cell lung cancer (NSCLC) and poor performance status. $\mathrm{Br}$ J Cancer 1992; 65: 934 - 941

${ }^{98}$ Medical Research Concil Lung Cancer Working Party. Randomized trial of palliative two-fraction versus more intensive 13 -fraction radiotherapy for patients with inoperable non-small-cell lung cancer and good performance status. Clinical Oncol 1996; 8: 167-175

${ }^{99}$ Speiser BL, Spratling L. Remote afterloading brachytherapy for the local control of endobronchial carcinoma. Int J Radiation Oncology Biol Phys 1993; 25: 579-587

${ }^{100}$ Freitag L, Tekolf E, Stamatis G, Montag M, Greschuchna D. Three years experience with a new balloon catheter for the management of hemoptysis. Europ Res J 1994; 7: 2033 - 2037

101 Stoll JF, Bettmann MA. Bronchial artery embolization to control hemoptysis: a review. Cardiovasc Intervent Radiol 1988; 11: 263-269

102 Zhang JS, Cui ZP, Wang MQ, Yang L. Bronchial arteriography and transcatheter embolization in the management of hemoptysis. Cardiovasc Intervent Radiol 1994; 17: 276-279

${ }^{103}$ Deutsche Gesellschaft für Pneumologie. Empfehlungen zur bronchoskopischen Behandlung tracheobronchialer Verschlüsse, Stenosen und muraler maligner Tumoren. Pneumologie 1998; 52: 243-248

104 Mathissen DJ, Grillo HC. Endoscopic relief of malignant airway obstruction. Ann Thorac Surg 1998; 48: 469-475 
${ }^{105}$ Cavaliere S, Foccoli P, Tonielli C, Feijo S. Nd-YAF laser therapy in lung cancer. An 11 year experience with 2253 applications in 1585 patients. J Bronchol 1994; 1: 105-111

106 Macha HN, Becker KO, Kemmer HP. Pattern of failure and survival in endobronchial laser resection: a matched pair study. Chest 1994; 105: $1668-1672$

107 Vergnon JM, Mathur PN. Cryotherapy for endobronchial disorders. In: Boliger CT, Mathur PN (Hrsg). Interventional Bronchoscopy Prog Respir Res Basel: Karger, 2000; Vol 30: 133 - 145

108 Sutedja G, van Boxem TJ, Schramel FM, Felius v C, Postmus PE. Endobronchial electrocautery is an excellent alternative for Nd: YAG laser to treat airway tumors. J Bronchol 1997; 4: 101-105

109 Sutedja G, Bolliger C. Endothelial electrocautery and argon plasma coagulation. In: Bolliger CT, Mathur PN (Hrsg). Interventional Bronchoscopy Prog Respir Res Basel: Karger, 2000; 30: 120-132

110 Maiwand MO, Homasson JP. Cryotherapy for tracheobronchial disorders. In: Mathur PN, Beamis JF (Hrsg). Clinics in Chest Medicine Philadelphia: Saunders, 1995; Vol 16: 427-443

111 Sutedja TG, Postmus PE. Photodynamic therapy in lung cancer. A review. J Photochem Photobiol B 1996; 36: 199-204

${ }^{112}$ Freitag L, Korupp A, Itzigehl I, Dankwart F, Tekolf E, Reichle G, Kullmann HJ, Macha HN. Erfahrungen mit Fluoreszenzdiagnostik und photodynamischer Therapie im multimodalen Behandlungskonzept des operierten rezidivierenden Bronchialkarzinoms. Pneumologie 1996; 50: 693-699

113 George PJM, Garrett CPO, Nixon C, Hetzel MR, Nanson EM, Millard FJ. Laser treatment for tracheobronchial tumors: local or general anesthesia? Thorax 1987; 42: 656-660

114 Macha HN, Wahlers B, Reichle G, von Zwehl D. Endobronchial radiation therapy for obstructing malignancies: ten years' experience with iridium-192 high-dose radiation brachytherapy afterloading technique in 365 patients. Lung 1995; 173: $271-280$

115 Huber RM, Fischer R, Hautmann H, Pollinger B, Wendt T, Müller-Wening D, Häussinger K. Palliative endobronchial bradytherapy for central lung tumors. A prospective, randomized comparison of two fractionation schedules. Chest 1995; 107: 463-470

116 Huber RM, Fischer R, Hautmann H, Pollinger B, Häussinger K, Wendt T. Does additional brachytherapy improve the effect of external irradiation? A prospective, randomized study in central tumors. Int J Radiat Oncol Biol Phys 1997; 38: 533 - 540

117 Freitag L. Tracheobronchial stents. In: Bolliger CT, Mathur PN (Hrsg). Interventional Bronchoscopy Pro Respir Res Basel: Karger, 2000; 30: $171-186$

118 Sutedja G, Schramel F, van Kralingen K, Postmus PE. Stent placement is justifiable in endstage patients with malignant airway tumors. Respiration 1995; 62 : $148-150$

119 Silvestri GA, Handy J, Lackland D, Corley E, Reed CE. Specialists achieve better outcomes than generalists for lung cancer surgery [see comments]. Chest 1998; 114: 675-680

120 Duque JL, Ramos G, Castrodeza J, Cerezal J, Castanedo M, Yuste MG, Heras F. Early complications in surgical treatment of lung cancer: a prospective, multicenter study. Grupo Cooperativo de Carcinoma Broncogenico de la Sociedad Espanola de Neumologia y Cirugia Toracica Ann Thorac Surg 1997; 63: $944-950$

121 Ginsberg RJ, Hill LD, Eagan RT, Thomas P, Mountain CF, Deslauriers J, Fry WA, Butz RO, Goldberg M, Waters PF. Modern thirty-day operative mortality for surgical resections in lung cancer. J Thorac Cardiovasc Surg 1983; 86: 654-658

122 Warren WH, Faber LP. Segmentectomy versus lobectomy in patients with stage I pulmonary carcinoma. J Thorac Cardiovasc Surg 1994; 107: $1087-1094$

${ }^{123}$ Wahi R, McMurtrey MJ, DeCaro LF, Mountain CF, Ali MK, Smith TL, Roth JA. Determinants of perioperative morbidity and mortality after pneumonectomy. Ann Thorac Surg 1989; 48: $33-37$

${ }^{124}$ Klemperer J, Ginsberg RJ. Morbidity and mortality after pneumonectomy. Chest Surg Clin N Am 1999; 9: 515-525

${ }^{125}$ Gaissert HA, Mathisen DJ, Moncure AC, Hilgenberg AD, Grillo HC, Wain JC. Survival and function after sleeve lobectomy for lung cancer. J Thorac Cardiovasc Surg 1996; 111: 948 - 953

126 Bach P, Cramer L, Schrag D, Downey R, Gelfand S, Begg C. The influence of hospital volume on survival after resection of lung cancer. $\mathrm{N}$ Engl J Med 2001; 345: $181-188$

127 Sugi K, Kaneda Y, Esato K. Video-assisted thoracoscopic lobectomy achieves a satisfactory long-term prognosis in patients with clinical stage IA lung cancer. World J Surg 2000; 24: 27-30
${ }^{128}$ Naruke T, Tsuchiya R, Kondo H, Nakayama H, Asamura H. Lymph node sampling in lung cancer: how should it be done? Eur J Cardiothorac Surg 1999; 16 Suppl 1: S17-S24

${ }^{129}$ McKenna-RJ J, Wolf RK, Brenner M, Fischel RJ, Wurnig P. Is lobectomy by video-assisted thoracic surgery an adequate cancer operation? Ann Thorac Surg 1998; 66: 1903-1908

${ }^{130}$ Mack MJ, Scruggs GR, Kelly KM, Shennib H, Landreneau RJ. Video-assisted thoracic surgery: has technology found its place? Ann Thorac Surg 1997; 64: $211-215$

131 Bernard A. Resection of pulmonary nodules using video-assisted thoracic surgery. The Thorax Group. Ann Thorac Surg 1996; 61: 202 - 204

${ }^{132}$ Mountain C, Dresler C. Regional lymphnode classification for lung cancer staging. Chest 1997; 111: $1718-1723$

133 Passlick B, Thetter O. Lymph node documentation and lymphadenectomy in bronchial carcinomas. Results of a survey in Germany. Chirurg 1997; 68: 601-605

${ }^{134}$ Schildberg FW, Dienemann H, Hoffmann H. Lymphadenektomie bei Bronchialkarzinomen: Fakten und Fiktion. Zentralbl 1996; 121: 96- 101

135 Izbicki JR, Thetter O, Habekost M, Karg O, Passlick B, Kubuschok B, Busch C, Haeussinger K, Knoefel WT, Pantel K. Radical systematic lymphadenectomy in non-small cell lung cancer - A prospective controlled randomized clinical trial. Brit J Surg 1994; 81: 229-235

${ }^{136}$ Izbicki JR, Passlick B, Pantel K, Pichlmeier U, Hosch SB, Karg O, Thetter $O$. Effectiveness of radical systematic mediastinal lymphadenectomy in patients with resectable non-small cell lung cancer - Results of a prospective randomized study. Ann Surg 1998; 227: 138-144

137 Luketich JD, Burt ME. Does resection of adrenal metastases from nonsmall-cell lung cancer improve survical? Ann Thorac Surg 1996; 62: $1614-1616$

${ }^{138}$ Mussi A, Pistolesi M, Lucchi M et al. Resection of single brain metastasis in non-small-cell lung cancer: prognostic factors. J Thorac Cardiovasc Surg 1996; 112: 146-153

139 Porte HL, Roumilhac D, Graziana JP et al. Adrenalectomy for a solitary adrenal metastasis form lung cancer. Ann Thorac Surg 1998; 65: $331-335$

140 Naruke T, Tsuchiya R, Kondo H, Asamura H, Nakayama H. Implications of staging in lung cancer. Chest 1997; 112: 242S-248S

${ }^{141}$ Mountain CF. The biological operability of stage III non-small cell lung cancer. Ann Thorac Surg 1985; 40: 60-64

142 Inoue K, Sato M, Fujimara S, Sakurada A, Takahashi S, Usuda K, Kondo T, Tanita T, Handa M, Saito Y. Prognostic assessment of 1310 patients with non-small-cell lung cancer who underwent complete resection from 1980 to 1993. J Thorac Cardiovasc Surg 1998; 116: 407-411

${ }^{143}$ Sagawa M, Sakurada A, Fujimara S, Sato M, Takahashi S, Usuda K, Endo C, Aikawa H, Kondo T, Saito Y. Five-year survivors with resected pN2 nonsmall cell lung carcinoma. Cancer 1999; 85: 864-868

${ }^{144}$ Kreisman H, Wolkove N, Quoix E. Small cell lung cancer presenting as a solitary pulmonary nodule. Chest 1992; 101: $225-231$

${ }^{145}$ Fujimori K, Yokoyama A, Kurita Y, Terashima M. A pilot phase 2 study of surgical treatment after induction chemotherapy for resectable stage I to IIIA small cell lung cancer. Chest 1997; 111: 1089-1093

${ }^{146}$ Elias AD. Small cell lung cancer: state-of-the-art therapy in 1996. Chest 1996; 112: 251S-258S

147 Osterlind K, Hansen M, Hansen HH, Dombernowsky P, Rorth M. Treatment policy of surgery in small cell carcinoma of the lung: retrospective analysis of a series of 874 consecutive patients. Thorax 1985; 40: $272-277$

148 Lad T, Piantadosi S, Thomas P, Payne D, Ruckdeschel J, Giaccone G. A prospective randomized trial to determine the benefit of surgical resection of residual disease following response of small cell lung cancer to combination chemotherapy. Chest 1994; 106: 320S-323S

${ }^{149}$ Fox W, Scadding JG. Medical Research Council comparative trial of surgery and radiotherapy for primary treatment of small-celled or oat-cell carcinoma of bronchus. Ten-year follow-up. Lancet 1973; 2: 63-65

150 Müler LC, Salzer GM, Huber H, Prior C, Ebner I, Frommhold H, Prauer HW. Multimodal therapy of small cell lung cancer in TNM stages through IIIa. Ann Thorac Surg 1992; 54: 493-497

${ }^{151}$ Eberhardt W, Stamatis G, Stuschke M, Wilke H, Muller MR, Kolks S, Flasshove M, Schutte J, Stahl M, Schlenger L, Budach V, Gerschuchna D, Stuben G, Teschler H, Sack H, Seeber S. Prognostically orientated multimodality treatment including surgery for selected patients of small-cell lung cancer patients stages IB to IIIB: long-term results of a phase II trial. Br J Cancer 1999; 81: 1206 - 1212 
152 Armstrong J. Target volume definition for three-dimensional conformal radiation therapy of lung cancer. Br J Radiol 1998; 71: 587-594

153 Graham MV, Prudy JA, Emamai B, Harms W, Bosch W, Lockett MA, Perez CA. Clinical dose-volume histogramm analysis for pneumonitis after 3D treatment for non-small cell lung cancer (NSCLC). Int J Radiat Oncol Biol Phys 1999; 45: 323 - 329

${ }^{154}$ Marks L, Munley MT, Bentel GC, Zhou SM, Hollis D, Scarfone C, Sibley G, Kong FM, Jirtle R, Jaszczak R, Coleman RE, Tapson V, Anscher M. Physical and biological predictors of changes in whole lung function following thoracic irradiation. Int J Radiat Oncol Biol Phys 1997; 39: $563-570$

${ }^{155}$ Armstrong J, Raben A, Zelefsky M, Burt M, Leibel S, Burman C, Kutcher G, Harrison L, Hahn C, Ginsberg R, Rusch V, Kris M, Fuks Z. Promising survival with three-dimensional conformal radiation therapy for non-small cell lung cancer. Radiother Oncol 1997; 44: 17-22

${ }^{156}$ De Ruysscher D, Vansteenkiste J. Chest radiotherapy in limited-stage small cell lung cancer: facts, questions, prospects. Radiother Oncol 2000; 55: $1-9$

${ }^{157}$ Royal College of Radiologists. Guidelines on the non-surgical management of lung cancer. Clinical Oncology 1999; 11: S1 - S53

158 Cox J, Azarnia N, Byhardt RW, Shin KH, Emami B, Pajak TF. A randomized phase I/II trial of hyperfractionated radiation therapy with total doses of $60.0 \mathrm{~Gy}$ to $79.3 \mathrm{~Gy}$ : possible survival benefit with greater than or equal to $69.6 \mathrm{~Gy}$ in favorable patients with Radiation Therapy Oncology Group stage III non-small-cell lung carcinoma: report of Radiation Therapy Oncology Group 83-11. J Clin Oncol 1990; 9: $1543-1555$

159 Appold S, Baumann M, Neidt F, Herrmann T. Ergebnisse der Bestrahlung inoperabler nichtkleinzelliger Bronchialkarzinome im Stadium III mit 25 Gy in fünf Fraktionen. Strahlenther Onkol 1999; 175: $267-270$

${ }^{160}$ McQuay HJ, Collins SL, Carroll D, Moore RA. Radiotherapy for the palliation of painful bone metastases. Cochrane Database Syst Rev 2000; CD001793

${ }^{161}$ Coia LR, Aaronson N, Linggood R, Loeffler J, Priestman TJ. A report of the consensus workshop panel on the treatment of brain metastases. Int J Radiat Oncol Biol Phys 1992; 23: $223-227$

162 Koswig S, Budach V. Remineralisation und Schmerzlinderung von Knochenmetastasen nach unterschiedlich fraktionierter Strahlentherapie (10mal 3 Gy vs. 1 mal 8 Gy). Strahlentherapie Onkol 1999; 175: $500-508$

${ }^{163}$ Nestle U, Nieder C, Walter K, Abel U, Ukena D, Sybrecht GW, Schnabel K. A palliative accelerated irradiation regimen for advanced nonsmall-cell lung cancer vs. Conventionally fractionated $60 \mathrm{~Gy}$ : results of a randomized equivalence study. Int J Radiat Oncol Biol Phys 2000; 48: $95-103$

${ }^{164}$ Steenland E, Leer J, van Houwelingen H, Post WJ, van den Hout WB, Kievit J, de Haes H, Martijn H, Oei B, Vonk E, van der Stehen-Banasik E, Wiggenraad RGJ, Hoogenhout J, Warlam-Rodenhuis C, van Tienhoven G, Wanders R, Pomp J, van Reijn M, van Mierlo T, Rutten E. The effect of a single fraction compared to multiple fractions on painful bone metastases: a global analysis of the Dutch bone metastasis study. Radiother Oncol 1999; 52: $101-109$

165 Wolf M, Pritsch M, Drings P, Hans K, Schroeder M, Flechtner H, Heim M, Hruska D, Mende S, Becker H, Dannhäuser J, Lohmüller R, Gropp C, Gassel WD, Holle R, Havemann K. Cyclic-alternating versus responseoriented chemotherapy in small-cell-lung cancer: a German multicenter randomized trial of 321 patients. J Clin Oncol 1991; 9: 614-624

${ }^{166}$ Murray N, Livingston RB, Shepherd FA, James K, Zee B, Langleben A, Kraut M, Bearden J, Goodwin JW, Grafton C, Turrisi A, Walde D, Croft H, Osoba D, Ottaway J, Gandara D. Randomized study of CODE versus alternating CAV/EP for extensive-stage small-cell lung cancer: an Intergroup Study of the National Cancer Institute of Canada Clincial Trials Group and the Southwest Oncology Group. J Clin Oncol 1999; 8 : 2300-2308

167 Souhami RL, Rudd R, Ruiz de Elvira MC, James L, Gower N, Harper PG, Tobias JS, Partridge MR, Davison AG, Trask C, Spiro SG. Randomized trial comparing weekly versus 3-week chemotherapy in small-cell lung cancer: a Cancer Research Campaign trial. J Clin Oncol 1994; 12: $1806-1813$

${ }^{168}$ Arriagada R, Le Chevalier T, Pignon JP, Riviere A, Monnet I, Chomy P, Tuchais C, Tarayre M, Ruffie P. Initial chemotherapeutic doses and survival in patients with limited small-cell lung cancer. N Engl J Med 1993; 329: $1848-1852$
169 Johnson DH, Carbone DP. Increased Dose-Intensity in Small-Cell Lung Cancer: A Failed Strategy? J Clini Oncol 1999; 17: 2297-2298

${ }^{170}$ Chute JP, Chen T, Feigal E, Simon R, Johnson D. Twenty years of Phase III Trials for Patients with Extensive-Stage Small-Cell Lung Cancer. Perceptible Progress. J Clin Oncol 1999; 17: 1794-1801

${ }^{171}$ Kosmidis PA, Samantas E, Fountzilas G, Pavlidis N, Apostolopoulou F, Skarlos D. Cisplatin/etoposide versus carboplatin/etoposide chemotherapy and irradiation in small cell lung cancer: a randomized phase III study. Hellenic Cooperative Oncology Group for Lung Cancer Trials. Semin Oncol 1994; 21: 23-30

172 Medical Research Council Lung Cancer Working Party. Comparison of oral etoposide and standard intravenous multidrug chemotherapy for small-cell lung cancer. A stopped multicentre randomised trial. Lancet 1996; 348: $563-566$

173 Medical Research Council Lung Cancer Working Party. Randomised trial of four-drug versus less intensive two-drug chemotherapy in the palliative treatment of patients with small cell lung cancer (SCLC) and poor prognosis. B J Cancer 1996; 73: 406-413

174 Ardizzoni A, Hansen H, Dombernowsky P, Gamucci T, Kaplan S, Postmus P, Giaccone G, Schaefer B, Wanders J, Verweij J. Topotecan an new drug in the second-line treatment of small-cell lung cancer: A phase II study of patients with refractory and sensitive disease. J Clin Oncol 1997; 15: 2090-2096

175 Groen HJM, Fokkema E, Biesma B, Kwa B, van Putten JWG, Postmus PE, Smit EF. Paclitaxel and Carboplatin in the Treatment of Small-Cell Lung Cancer Patients Resistant to Cyclophosphamide, Doxorubicin, and Etoposide: A Non-Cross-Resistant Schedule. J Clin Oncol 1999; 17: $927-932$

176 von Pawel J, Schiller JH, Shephard FA, Fields SZ, Kleisbauer JP, Chrysson NG, Stewart DJ, Clark PI, Palmer MC, Depierre A, Carmichael J, Krebs JB, Ross G, Lane SR, Gralla R. Topotecan Versus Cyclophosphamide, Doxorubicin, and Vincristine for the Treatment of Recurrent Small-Cell lung Cancer. J Clin Oncol 1999; 17: 658-667

177 Masuda N, Matusi K, Negoro S, Takifuji N, Takeda K, Yana T, Kobayashi M, Hirashima T, Kusunoki Y, Ushijima S, Kawase I, Tada T, Sawaguchi H, Fukuoka M. Combination of Irinotecan and Etoposide for treatment of refractory or relapsed small cell lung cancer. J Clin Oncol 1998; 16: 3329-3334

178 Ginsberg R, Vokes E, Raben A. Non-small cell lung cancer. In: DeVita V, Hellman S, Rosenberg S (Hrsg). Cancer Philadelphia: LippincottRaven, 1997: 858

179 Marino P, Preatoni A, Cantoni A, Bucceri G. Single-agent chemotherapy versus combination chemotherapy in advanced NSCLC. A quality and meta-analysis study. Lung Cancer 1995; 13: 1-12

${ }^{180}$ Lilienbaum RC, Langenberg P, Dickersin K. Single agent chemotherapy versus combination chemotherapy in patients with advanced NSCLC: A meta-analysis of response, toxicity and survival. Cancer 1998; 82: $116-126$

181 Perng RP, Chen YM, Ming-Liu J, Tsai CM, Lin WC, Yang KY, WhangPeng J. Gemcitabine versus the combination of cisplatin and etoposide in patients with inoperable non-small-cell lung cancer in a phase II randomized study. J Clin Oncol 1997; 15: 2097-2102

182 Manegold C, Bergmann B, Chemaissani A, Dornhoff W, Drings P, Kellokumpu-Lehtinen P, Liippo K, Mattson K, von Pawel J, Ricci S, Sederholm C, Stahel RA, Wagenius G, van Walree N, ten Bokkel-Huinink W. Single agent gemcitabine versus cisplatin-etoposide: early results of a randomized phase II study in locally advanced or metastatic nonsmall cell lung cancer. Ann Oncol 1997; 8: 525-529

${ }^{183}$ Frasci G, Lorusso V, Panza N, Comella P, Nicollela G, Bianco A, De Cataldis G, Ianelli A, Bilancia D, Belli M, Massidda B, Piantedosi F, Comella $G$, De Iena M. Gemcitabine plus vinorelbine versus vinorelbine alone in elderly patients with advanced NSCLC. J Clin Oncol 2000; 18: $2529-2536$

184 The Elderly Lung Cancer Vinorelbine Italian Study Group (ELVIS). Effects of vinorelbine on quality of life and survival of elderly patients with advanced non-small-cell lung cancer. J Natl Cancer Inst 1999; 91: $66-72$

185 Larsen H, Sörensen JB, Nielsen AL, Dombernowsky P, Hansen H. Evaluation of the optimal duration of chemotherapy in phase II trials for inoperable NSCLC. Ann Oncol 1995; 6: 993-997

${ }^{186}$ Smith IE, O'Brien MER, Norton A, Ashley S, Webb A, Nicolson M, Hickish T, Talbot T, Mansi J. Duration of chemotherapy for advances NSCLC: A phase III randomized trial of 3 versus 6 courses of mitomycin, vinblastine, cisplatin (MVP). Proc Am Soc Clin Oncol 1998; (abs. 1759) 
187 Giaccone G, Splinter TA, Debruyne C, Kho GS, Lianes P, van Zandwijk N, Penucci MC, Scagliotti G, van Meerbeeck J, van Hoesel Q Curran D, Sahmoud T, Postmus PE. Randomized study of paclitaxel-cisplatin versus cisplatin-teniposide in patients with advanced non-small-cell lung cancer. The European Organization for Research and Treatment of Cancer Lung Cancer Cooperative Group. J Clin Oncol 1998; 16: $2133-2141$

188 Cardenal F, Lopez-Cabrerizo P, Anton A, Rosell R. Randomized phase III study of gemcitabine-cisplatin versus etoposide-cisplatin in the treatment of locally advanced or metastatic NSCLC. J Clin Oncol 1999; 17: $12-18$

189 Le Chevalier T, Brisgand D, Douillard J, Pujol J, Alberola V, Monnier A, Riviere A, Lianes P, Chomy P, Cigolari S, Gottfried M, Ruffie P, Panizo A, Gaspard M, Ravaioli A, Besenval M, Besson F, Martinez A, Berthaud P, Tursz T. Randomized study of Vinorelbine and Cisplatin versus Vindesine and Cisplatin versus Vinorelbine alone in advanced nonsmall-cell lung cancer: Results of a European multicenter trial including 612 patients. J Clin Oncol 1994; 12: 360-367

${ }^{190}$ Klasterski J, Sculier J, Lacoix H et al. A randomized study comparing cisplatin or Carboplatin with etoposide in patients with advanced NSCLC. EORTC Protocol 07861. J Clin Oncol 1990; 8: 1556-1562

191 Biesma B, Smit EF, Postmus PE. A dose and schedule finding study of gemcitabine and etoposide in patients with progressive NSCLC after platinum containing chemotherapy. Lung Cancer 1999; 24: 115-121

192 Fossella F, DeVore R, Kerr R, Crawford J, Natale R, Dunphy F, Kalman L, Miller V, Lee J, Gandara D, Karp D, Vokes E, Kris M, Kim Y, Gamza S, Hammershaimb L and the TAX 320 non-small cell lung cancer study group. Randomized phase III trial of docetaxel versus vinorelbine or ifosfamide in patients with advanced non-small cell lung cancer previously treated with platinum-containing chemotherapy regimens. J Clin Oncol 2000; 18: 2354-2362

${ }^{193}$ Shepherd FA, Dancey J, Ramlau R, Mattson K, Gralla R, O'Rourke M, Levitan N, Gressot L, Vincent M, Burkes R, Coughlin S, Kim Y, Berille J. Prospective randomized trial of Docetaxel versus best Supportive Care in patients with non-small-cell lung cancer previously treated with platinum-based chemotherapy. J Clin Oncol 2000; 18: 2095-2103

${ }^{194}$ Sutedja G, Postmus PE. Bronchoscopic treatment of lung tumors. Lung cancer 1994; 11: 1 - 117

195 Venmans BJ, van Boxem TJ, Smit EF, Postmus PE, Sutedja TG. Outcome of bronchial carcinoma in situ. Chest 2000; 117: 1572-1576
196 Sheski FD, Mathur PN. Endoscopic treatment of early-stage lung cancer. Cancer Control 2000; 7: 35-44

${ }^{197}$ Koike T, Terashima M, Takizawa T, Tsukada H, Yokoyama A, Kurita Y, Honma K. Surgical results for centrally-located early stage lung cancer. Ann Thorac Surg 2000; 70: 1176-1179

198 Johnson BE. Second lung cancer in patients after treatment for an initial lung cancer. J Natl Cancer Inst 1998; 90: 1335-1345

199 Edell ES, Cotese DA. Photodynamic therapy in the management of early superficial squamous cell carcinoma as an alternative to surgical resection. Chest 1992; 102: 1319-1322

200 Perol M, Caliandro R, Pommier P, Malet C, Montbarbon X, Carrie C, Ardiet JM. Curative irradiation of limited carcinomas with high-dose brachytherapy. Chest 1997; 111: 1417-1423

201 van Boxem TJ, Venmans BJ, Schramel FM, van Mourik JC, Golding RP, Postmus PE, Sutedja TG. Radiographically occult lung cancer treated with fibreoptic bronchoscopic electrocautery: a pilot study of a simple and inexpensive technique. Eur Respir J 1998; 11: 169-172

202 Deygas N, Froudarakis ME, Ozenne G, Jouve S, Fournel P, Vergnon JM. Cryotherapy in early superficial bronchogenic carcinoma. Eur Respir J 1998; 12 (Suppl 28): 266

${ }^{203}$ Furuse K, Fukuoka M, Kato H, Horrai T, Kubota T, Kodama N, Kusunoki Y, Takifuji N, Okunaka T, Konaka C, Wada H, Hayata Y. A prospective phase II study on photodynamic therapy with photofrin II for centrally located early-stage lung cancer. J Clin Oncol 1993; 11: 1852 - 1857

${ }^{204}$ Kato H, Okunaka T, Shimatani H. Photodynamic therapy for early stage bronchogenic carcinoma. J Clin Laser Med Surg 1996; 14: 235-238

205 Cortese DA, Edell ES, Kinsey JH. Photodynamic therapy for early stage squamous cell carcinoma of the lung. Mayo Clin Proc 1997; 72: $595-602$

${ }^{206}$ Martini N. Surgical treatment of non-small cell lung cancer by stage. Semin Surg Oncol 1990; 6: 248-254

${ }^{207}$ Kotlyarov E, Rukosuyev AA. Long-term results and patterns of disease recurrence after radical operations for lung cancer. J Thorac Cardiovasc Surg 1991; 102: 24-28

208 The Lung Cancer Study Group. Patterns of failure in patients with resected stage I und II non-small cell carcinoma of the lung. Ann Surg 1987; 205: 67

${ }^{209}$ Pairolero PC, Williams DE, Bergstralh EJ, Piehler JM, Bernatz PE, Payne WS. Postsurgical stage I bronchogenic carcinoma: morbid implications of recurrent disease. Ann Thorac Surg 1984; 38: 331 - 338 